\title{
Article \\ Critical Analysis of Nonlinear Base-Isolated Building Considering Soil-Structure Interaction under Impulsive and Long-Duration Ground Motions
}

\author{
Hiroki Akehashi and Izuru Takewaki * \\ Department of Architecture and Architectural Engineering, Graduate School of Engineering, Kyoto University, \\ Kyotodaigaku-Katsura, Nishikyo, Kyoto 615-8540, Japan; fm-akehashi@archi.kyoto-u.ac.jp \\ * Correspondence: takewaki@archi.kyoto-u.ac.jp
}

Citation: Akehashi, H.; Takewaki, I. Critical Analysis of Nonlinear Base-Isolated Building Considering Soil-Structure Interaction under Impulsive and Long-Duration Ground Motions. Geotechnics 2021, 1, 76-94. https://doi.org/10.3390/ geotechnics1010005

Academic Editor: Kenneth Gavin

Received: 12 June 2021

Accepted: 25 June 2021

Published: 30 June 2021

Publisher's Note: MDPI stays neutral with regard to jurisdictional claims in published maps and institutional affiliations.

Copyright: (c) 2021 by the authors. Licensee MDPI, Basel, Switzerland. This article is an open access article distributed under the terms and conditions of the Creative Commons Attribution (CC BY) license (https:// creativecommons.org/licenses/by/ $4.0 /)$.
Abstract: Critical responses are investigated for nonlinear base-isolated buildings considering soilstructure interaction under near-fault ground motions and long-duration ground motions. A double impulse and a multi impulse are employed to simulate the nonlinear critical responses of the models under such ground motions. The base-isolation story is assumed to consist of lead rubber bearings and to have a bilinear force-deformation relation. Two types of critical timings for a MDOF building model supported by a swaying-rocking spring-dashpot system are derived: (1) the timing that maximizes the total input energy to the whole system and (2) the timing that maximizes the instantaneous input energy to the base-isolated building excluding the swaying-rocking system. These two types of critical timings are compared through numerical examples. Finally, time-history response analyses were conducted under the critical double impulse, the corresponding one-cycle sine wave, and the critical multi impulse. The effect of the soil-structure interaction on the maximum responses of the nonlinear base-isolated building is clarified.

Keywords: nonlinear base-isolation; soil-structure interaction; critical response; resonance; double impulse; near-fault ground motion; multi impulse; long-duration ground motion

\section{Introduction}

Many structural vibration control systems have been developed so far (see [1-3]). In particular, seismic isolation systems greatly reduce both the floor acceleration responses and the deformation responses of the superstructure, although the isolation systems require relatively high initial costs. Base-isolation systems are also applicable for seismic retrofitting of existing buildings, and they do not require the reinforcement of the structural members, depending on the state of the existing building [4]. Base-isolation systems have been widely investigated and have changed the structural design concept. Jangid and Kelly [5] compared several base-isolation systems in view of the effectiveness for near-fault ground motions. Tsai and Kelly [6] investigated the undesirable effect on the superstructure caused by heavily damped base-isolation systems.

Although base-isolation systems are highly effective for moderate-level ground motions specified in the code of building structural design, they are not effective for motions with large ground displacement, such as fling-step motions (for example, Chi-chi earthquake (1999), Kumamoto earthquake (2016)). Such ground motions cause a large deformation in the base-isolation story, and it leads to the failure of the isolation equipment, the collision of the structure to the retaining wall, and the damage to the superstructure [7].

Research on soil-structure interaction has also been tackled by many researchers (see [8]). Numerical analysis methods of soil-structure interaction have been established, such as a finite element method, an equivalent linearization method, a boundary element method, a frequency analysis method, a substructure method, and so on [9]. The remarkable development of computers realized the use of these advanced methods. Some researchers 
pointed out the importance of incorporating soil-structure interaction properly into the structural design [10-13]. It is noted that, in the case of the designs of base-isolated buildings on soft ground, the stiffness of the isolation story must be designed to be small so that the equivalent lowest-mode damping ratio of the whole system including the ground stiffness becomes high.

In general, base-isolated buildings should be constructed on hard ground because soft ground may induce long-period ground motion components. For example, when the Great East Japan earthquake (2011) occurred, high-rise buildings located far from the epicenter exhibited resonant responses [14]. When base-isolated buildings on soft ground exhibit resonant responses, the input to the base-isolated building by the base mat is amplified. This may significantly increase the responses of the superstructure and the base-isolation story.

The number of research studies on the effects of soil-structure interaction on baseisolated building are limited (for example, [15-21]). In particular, Luco formulated transcendental equations of nonlinear steady state responses of base-isolated buildings on flexible ground by using the equivalent linearization technique [22].

Akehashi et al. [23] and Akehashi and Takewaki [24] investigated the nonlinear critical response of a base-isolated building system considering soil-structure interaction under near-fault and far-fault earthquake ground motions by using a double impulse and a multi impulse. In those papers, a 4-DOF base-isolated building model, which consists of the superstructure, the base-isolation story, and the swaying-rocking spring-dashpot system of the ground, is transformed into a SDOF model. However, MDOF base-isolated building models should be treated directly to capture the effect of the soil-structure interaction precisely. For example, it is widely known that the high frequency components in the responses of the superstructure are excited due to the nonlinear response of the baseisolation story [25]. The reduced SDOF model is not enough to investigate whether this excitation of high frequency components is amplified by the decrease of the ground stiffness. However, the critical impulse timing for MDOF models supported by a swaying-rocking spring-dashpot system has never been clarified so far, and the critical responses of the model under double impulse and multi impulse have been hard to be derived.

In this paper, the critical responses are investigated for nonlinear base-isolated buildings considering soil-structure interaction under near-fault ground motions and longduration ground motions. A double impulse and a multi impulse are employed to simulate the nonlinear critical responses of the models under such different-type ground motions. The use of these ground motions enables the precise capturing of the effect of the soilstructure interaction on the response of base-isolated buildings, especially in the critical cases. The base-isolation story is assumed to consist of lead rubber bearings and have a bilinear force-deformation relation. It is noted that the superstructure is linear elastic because the base-isolation system greatly reduces the responses of superstructures. The two types of critical timings are derived for a MDOF building model supported by a swayingrocking spring-dashpot system: (1) the timing that maximizes the total input energy to the whole system and (2) the timing that maximizes the instantaneous input energy to the base-isolated building excluding the swaying-rocking system. These two types of critical timings are compared through numerical examples. Finally, time-history response analyses are conducted under the critical double impulse, the corresponding one-cycle sine wave, and the critical multi impulse. The effect of the soil-structure interaction on the maximum responses of the nonlinear base-isolated building is clarified.

In Section 2, a double impulse is introduced as the substitute of the fling-step ground motion. In Section 3, a base-isolated building considering soil-structure interaction is explained. In Section 4, the two types of critical timings of the double impulse are derived. In Section 5, numerical examples are shown to examine the effect of the soil-structure interaction on the maximum responses of the base-isolated building under the double impulse and the corresponding one-cycle sine wave. In Section 6, the effect of the soilstructure interaction on the maximum responses of the base-isolated building under the 
multi impulse is clarified through numerical examples. Section 7 is given for the discussion of the results and the conclusion is shown in Section 8.

\section{Double Impulse as Substitute of Fling-Step Ground Motion}

It has been clarified that a one-cycle sine wave and a double impulse effectively express the main characteristic of a fling-step motion [26-30]. The ground accelerations of the double impulse and the one-cycle sine wave (Figure 1) are expressed as follows.

$$
\begin{gathered}
\ddot{u}_{g}(t)=V \delta(t)-V \delta\left(t-t_{0}\right) \\
\ddot{u}_{g}(t)=\frac{\pi V_{p}}{2 t_{0}} \sin \left(\frac{\pi t}{t_{0}}\right) \quad\left(0 \leq t \leq 2 t_{0}\right)
\end{gathered}
$$

where $V$ is the input velocity amplitude of the double impulse, $t_{0}$ is the time interval of the two impulses, $V_{p}$ is the velocity amplitude of the one-cycle sine wave, and $\delta(t)$ is the Dirac delta function. The time $t$ in Equations (1) and (2) does not necessarily correspond to Figure 1. It is noted that these accelerations are given at the surface of the free-field ground. $V_{p}$ is set to $V_{p}=1.222 \mathrm{~V}$ so that the maximum value of the Fourier amplitude of the one-cycle sine wave coincides with that of the double impulse [28]. This adjustment also gives a good correspondence of the Fourier amplitude in the range of $0 \leq \omega t_{0} / \pi \leq 2$ (Figure 2). The adjusted one-cycle sine wave is called the 'corresponding one-cycle sine wave'. Especially in base-isolated buildings, the fundamental mode is dominant in the response. Therefore, when the input periods of these two ground accelerations coincide with the fundamental natural period of the base-isolated building, the response under the double impulse and that under the one-cycle sine wave correspond well.
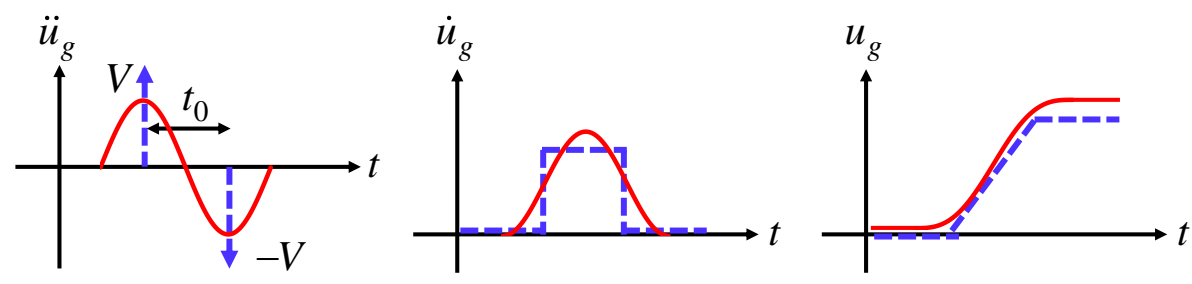

Figure 1. Double impulse and corresponding one-cycle sine wave.

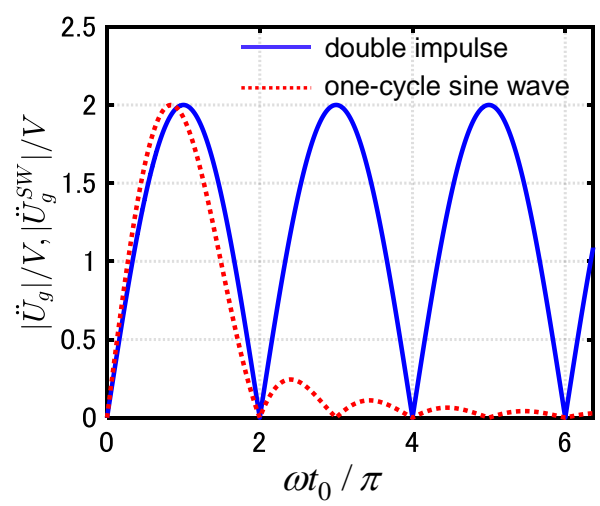

Figure 2. Fourier amplitudes of double impulse and corresponding one-cycle sine wave.

The use of the double impulse enables the capturing of the critical input period for elastic-plastic MDOF models without repetition. On the contrary, in the case of the onecycle sine wave, an iterative procedure with much computational effort is required to obtain the critical responses of the elastic-plastic MDOF models by parametrically changing the input period. On the other hand, the value of the ground acceleration of the double impulse is zero except at the two timings where the impulses act and only the free vibration occurs. Furthermore, the critical time interval of the two impulses, which maximizes the total 
input energy, can be obtained through time-history response analysis under only the first impulse. The critical time interval is derived in Section 4 for elastic-plastic MDOF models supported by a swaying-rocking spring-dashpot system.

\section{Base-Isolated Building Considering Soil-Structure Interaction}

Consider a base-isolated building on flexible ground (Figure 3). The number of stories of the superstructure is $N . m_{i}, k_{i}, c_{i}, I_{i}, H_{i}(i=1, \ldots, N)$ denote the $i$-th story mass, story stiffness, story damping coefficient, story mass moment of inertia, and the height of the $i$-th story mass from the base mat. The superstructure response is assumed to be elastic. The base-isolation story consists of lead rubber bearings and has a bilinear force-deformation relation. $m_{I}, k_{I}, \alpha_{I}, d_{y, I}, c_{I}, I_{I}, H_{I}$ denote the mass, the initial stiffness, the second stiffness ratio, the yield deformation, the damping coefficient, the mass moment of inertia, and the height from the base mat of the base-isolation story. The soil-structure interaction is modeled by a swaying-rocking spring-dashpot system using the well-known substructure method including the ground stiffness nonlinearity in the equivalent shear wave velocity. $m_{0}, r, I_{0}$ denote the mass of the base mat, the equivalent radius of the rigid circular base mat for evaluation of ground stiffness and damping in the substructure model, and the mass moment of inertia of the base mat. $k_{H}, c_{H}, k_{R}, c_{R}$ denote the swaying-rocking stiffnesses and damping coefficients of the spring-dashpot system.

$u_{i}, u_{I}, u_{0}, \theta$ denote the $i$-th story deformation of the superstructure, the deformation of the base-isolation story, the swaying displacement, and the angle of rotation of the base mat, and $\mathbf{u}=\left(u_{N}, \ldots, u_{1}, u_{I}, u_{0}, \theta\right)^{T}$. When the stiffness of the base-isolation story is in the range of the initial stiffness, the equation of motion is expressed by

$$
\mathbf{M u}+\mathbf{C} \dot{\mathbf{u}}+\mathbf{K u}=-\mathbf{M r} \ddot{u}_{g}
$$

where

$$
\begin{aligned}
& \mathbf{M}= \mathbf{T}^{T} \mathbf{M}_{r} \mathbf{T}, \quad \mathbf{C}=\operatorname{diag}\left(c_{N}, \ldots, c_{1}, c_{I}, c_{H}, c_{R}\right), \quad \mathbf{K}=\operatorname{diag}\left(k_{N}, \ldots, k_{1}, k_{I}, k_{H}, k_{R}\right), \quad \mathbf{r}=(0, \ldots, 0,1,0)^{T} \\
& \mathbf{u}_{r}=\left(u_{r, N}, \ldots, u_{r, 1}, u_{r, I}, u_{0}, \theta\right)^{T}=\mathbf{T u}, \quad \mathbf{M}_{r}=\operatorname{diag}\left(m_{N}, \ldots, m_{1}, m_{I}, m_{0}, I_{0}+I_{I}+\sum_{i=1}^{N} I_{i}\right) \\
& \mathbf{T}=\left(\begin{array}{ccccccc}
1 & \cdots & \cdots & 1 & 1 & 1 & H_{N} \\
0 & 1 & \cdots & 1 & 1 & 1 & H_{N-1} \\
\vdots & \ddots & \ddots & \vdots & \vdots & \vdots & \vdots \\
0 & \cdots & 0 & 1 & 1 & \vdots & H_{1} \\
0 & \cdots & \cdots & 0 & 1 & 1 & H_{I} \\
0 & \cdots & \cdots & \cdots & 0 & 1 & 0 \\
0 & \cdots & \cdots & \cdots & \cdots & 0 & 1
\end{array}\right), \quad \mathbf{T}^{-1}=\left(\begin{array}{ccccccc}
1 & -1 & 0 & \cdots & \cdots & 0 & H_{N-1}-H_{N} \\
0 & 1 & -1 & 0 & \cdots & 0 & H_{N-2}-H_{N-1} \\
\vdots & \ddots & \ddots & \ddots & \ddots & \vdots & \vdots \\
0 & \cdots & 0 & 1 & -1 & 0 & H_{I}-H_{1} \\
0 & \cdots & \cdots & 0 & 1 & -1 & -H_{I} \\
0 & \cdots & \cdots & \cdots & 0 & 1 & 0 \\
0 & \cdots & \cdots & \cdots & \cdots & 0 & 1
\end{array}\right)
\end{aligned}
$$

In Equation (5), $u_{r, i}=u_{0}+u_{I}+\sum_{j=1}^{i} u_{j}+H_{i} \theta$ is the $i$-th story displacement from the ground, and $u_{r, I}=u_{0}+u_{I}+H_{I} \theta$ is the base-isolation story displacement from the ground. Especially in the case of $N=1, \mathbf{M}$ is expressed as follows:

$$
\mathbf{M}=\left(\begin{array}{cccc}
m_{1} & m_{1} & m_{1} & m_{1} H_{1} \\
m_{1} & m_{1}+m_{I} & m_{1}+m_{I} & m_{1} H_{1}+m_{I} H_{I} \\
m_{1} & m_{1}+m_{I} & m_{1}+m_{I}+m_{0} & m_{1} H_{1}+m_{I} H_{I} \\
m_{1} H_{1} & m_{1} H_{1}+m_{I} H_{I} & m_{1} H_{1}+m_{I} H_{I} & m_{1} H_{1}^{2}+m_{I} H_{I}^{2}+I_{0}+I_{1}+I_{I}
\end{array}\right)
$$



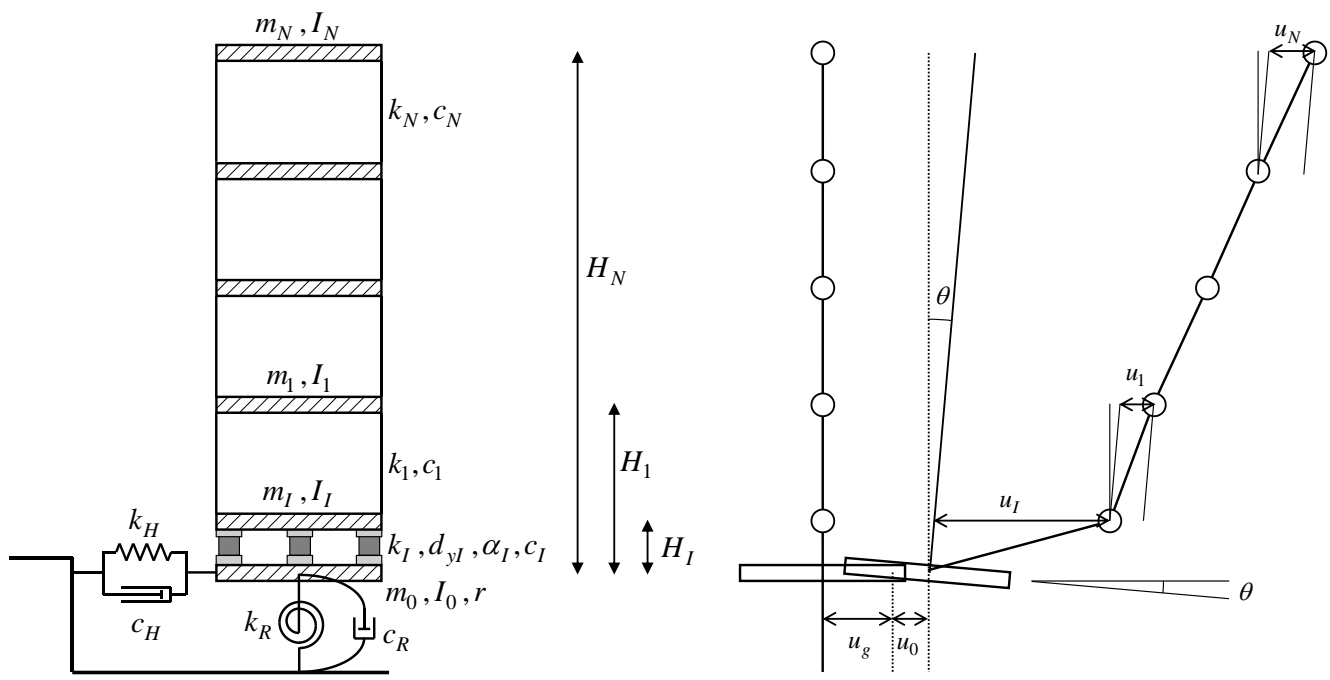

Figure 3. Nonlinear base-isolated building considering soil-structure interaction.

\section{Critical Impulse Timing}

Akehashi and Takewaki [31] derived the critical timing of the double impulse for elastic-plastic MDOF models. The critical timing is defined as the timing that maximizes the total input energy to the whole system. It is noted that the maximization of the total input energy is equal to the maximization of the input energy by the second impulse since the input energy by the first impulse is constant. In this section, the two types of critical timings are derived for a MDOF building model supported by a swaying-rocking spring-dashpot system: (1) the timing that maximizes the total input energy to the whole system (Section 4.1) and (2) the timing that maximizes the instantaneous input energy to the base-isolated building, excluding a swaying-rocking system (Section 4.2). These two types of critical timings are compared through numerical examples in Section 5.

\subsection{Critical Impulse Timing That Maximizes Total Input Energy to Whole System}

Consider the input energy to the whole system by the double impulse. Since the impulse input does not change the displacement at once, the input energy $E_{1}$ by the first impulse is expressed as

$$
\begin{aligned}
E_{1} & =\frac{1}{2}(V \mathbf{r})^{T} \mathbf{M}(V \mathbf{r})=\frac{1}{2} V^{2} \mathbf{r}^{T} \mathbf{M r}=\frac{1}{2} V^{2} \mathbf{r}^{T} \mathbf{T}^{T} \mathbf{M}_{r} \mathbf{T r} \\
& =\frac{1}{2} V^{2}(1, \ldots, 1,0) \mathbf{M}_{r}(1, \ldots, 1,0)^{T}=\frac{1}{2}\left(m_{0}+m_{I}+\sum_{i=1}^{N} m_{i}\right) V^{2}
\end{aligned}
$$

The value of $E_{1}$ is constant since the system is at rest before the first impulse input.

Consider next the input energy $E_{2}$ by the second impulse. $E_{2}$ can be derived by subtracting the kinetic energy just before the second impulse input from that just after the input.

$$
\begin{aligned}
E_{2} & =\frac{1}{2}(\dot{\mathbf{u}}+V \mathbf{r})^{T} \mathbf{M}(\dot{\mathbf{u}}+V \mathbf{r})-\frac{1}{2} \dot{\mathbf{u}}^{T} \mathbf{M} \dot{\mathbf{u}}=V \mathbf{r}^{T} \mathbf{M} \dot{\mathbf{u}}+\frac{1}{2} V^{2} \mathbf{r}^{T} \mathbf{M r} \\
& =V \mathbf{r}^{T} \mathbf{T}^{T} \mathbf{M}_{r} \mathbf{T}\left(\mathbf{T}^{-1} \dot{\mathbf{u}}_{r}\right)+\frac{1}{2} V^{2} \mathbf{r}^{T} \mathbf{M r} \\
& =V(1, \ldots, 1,0) \mathbf{M}_{r} \dot{\mathbf{u}}_{r}+\frac{1}{2}\left(m_{0}+m_{I}+\sum_{i=1}^{N} m_{i}\right) V^{2} \\
& =\left(m_{0} \dot{u}_{0}+m_{I} \dot{u}_{r, I}+\sum_{i=1}^{N} m_{i} \dot{u}_{r, i}\right) V+\frac{1}{2}\left(m_{0}+m_{I}+\sum_{i=1}^{N} m_{i}\right) V^{2}
\end{aligned}
$$

where $\dot{\mathbf{u}}$ is the velocity just before the second impulse input. Since the value of $E_{1}$ is constant, the maximization of the total input energy $\left(E_{1}+E_{2}\right)$ is equal to the maximization of the input energy $E_{2}$ by the second impulse. Since $E_{2}$ in Equation (9) can be regarded as function of $t_{0}$ because $t=t_{0}$ is substituted, the partial differentiation of $E_{2}$ with respect to $t_{0}$ leads to

$$
\frac{\partial E_{2}}{\partial t_{0}}=\left(m_{0} \ddot{u}_{0}+m_{I} \ddot{u}_{r, I}+\sum_{i=1}^{N} m_{i} \ddot{u}_{r, i}\right) V
$$


The input energy $E_{2}$ by the second impulse is maximized when the value of Equation (10) attains zero. $\left(m_{0} \ddot{u}_{0}+m_{I} \ddot{u}_{r, I}+\sum_{i=1}^{N} m_{i} \ddot{u}_{r, i}\right)$ in Equation (10) expresses the sum of the inertial force of the whole system. Moreover, the sum $\left(k_{H} u_{0}+c_{H} \dot{u}_{0}\right)$ of the forces by the swaying spring and the swaying dashpot of the ground is equal to $-\left(m_{0} \ddot{u}_{0}+m_{I} \ddot{u}_{r, I}+\right.$ $\left.\sum_{i=1}^{N} m_{i} \ddot{u}_{r, i}\right)$. This is because the value of the ground acceleration is zero after the first impulse input. The critical condition of the total input energy to the whole system is $\left(k_{H} u_{0}+c_{H} \dot{u}_{0}\right)=-\left(m_{0} \ddot{u}_{0}+m_{I} \ddot{u}_{r, I}+\sum_{i=1}^{N} m_{i} \ddot{u}_{r, i}\right)=0$.

\subsection{Critical Impulse Timing That Maximizes Instantaneous Input Energy to Base-Isolated} Building Excluding Swaying-Rocking Spring-Dashpot System

The change of the velocity response by one impulse input in the $\mathbf{u}_{r}$ coordinate system is expressed as follows:

$$
\mathbf{T}(V \mathbf{r})=V(1, \ldots, 1,0)^{T}
$$

The instantaneous input energy $E_{2}^{S}$ to the base-isolated building excluding the swayingrocking spring-dashpot system is expressed by

$$
\begin{aligned}
E_{2}^{S} & =\frac{1}{2}\left\{m_{I}\left(\dot{u}_{r, I}+V\right)^{2}+\sum_{=1}^{N} m_{i}\left(\dot{u}_{r, i}+V\right)^{2}\right\}-\frac{1}{2}\left\{m_{I} \dot{u}_{r, I}^{2}+\sum_{=1}^{N} m_{i} \dot{u}_{r, i}^{2}\right\} \\
& =V\left(m_{I} \dot{u}_{r, I}+\sum_{=1}^{N} m_{i} \dot{u}_{r, i}\right)+\frac{1}{2} V^{2}\left(m_{I}+\sum_{=1}^{N} m_{i}\right)
\end{aligned}
$$

The partial differentiation of $E_{2}^{S}$ with respect to $t_{0}$ provides

$$
\frac{\partial E_{2}^{S}}{\partial t_{0}}=V\left(m_{I} \ddot{u}_{r, I}+\sum_{i=1}^{N} m_{i} \ddot{u}_{r, i}\right)
$$

$E_{2}^{S}$ is maximized when the value of Equation (13) attains zero. $\left(m_{I} \ddot{u}_{r, I}+\sum_{i=1}^{N} m_{i} \ddot{u}_{r, i}\right)$ in Equation (13) expresses the sum of the inertial force of the base-isolated building excluding the swaying-rocking spring-dashpot system. The sum $\left(f_{I}+c_{I} \dot{u}_{I}\right)$ of the nonlinear restoring force and the damping force of the base-isolation story is equal to $-\left(m_{I} \ddot{u}_{r, I}+\sum_{i=1}^{N} m_{i} \ddot{u}_{r, i}\right)$. Therefore, the critical condition of the instantaneous input energy to the base-isolated building excluding the swaying-rocking spring-dashpot system is $\left(f_{I}+c_{I} \dot{u}_{I}\right)=-\left(m_{I} \ddot{u}_{r, I}+\right.$ $\left.\sum_{i=1}^{N} m_{i} \ddot{u}_{r, i}\right)=0$.

It is noted that the difference between the two critical conditions of the second impulse input is the inertial force at the basement $m_{0} \ddot{u}_{0}$. Therefore, these two types of critical timings are expected to be almost the same.

\section{Numerical Examples}

In this section, the time-history response analyses under the double impulse and the corresponding one-cycle sine wave are conducted. The two types of critical timings shown in Sections 4.1 and 4.2 are compared. The effect of the soil-structure interaction on the maximum responses of the base-isolated building is examined.

\subsection{Building Model}

The number of stories of the superstructure is $10(N=10)$. All the floor masses have the same value $\left(m_{i}=0.4 \times 10^{6} \mathrm{~kg}(\right.$ for $\left.i=1, \ldots, N)\right)$. The common story height is $4 \mathrm{~m}$ $\left(H_{i}=4 i+H_{I}(\mathrm{~m})\right.$ for $\left.i=1, \ldots, N\right)$. The distribution of story stiffnesses is a trapezoidal distribution and is characterized by $k_{1} / k_{10}=3$. The undamped fundamental natural period is $1.2 \mathrm{~s}$, and the structural damping ratio is 0.02 (stiffness proportional type). The mass moment of inertia of each floor is $I_{i}=\pi r^{2} m_{i} / 12($ for $i=1, \ldots, N)$.

The mass of the base-isolation story is $m_{I}=0.8 \times 10^{6} \mathrm{~kg}$. The height of the baseisolation story is $2 \mathrm{~m}\left(H_{I}=2 \mathrm{~m}\right)$. The base-isolation story is assumed to consist of lead rubber bearings and have a bilinear force-deformation relation. The yield deformation is $0.01 \mathrm{~m}\left(d_{y, I}=0.01 \mathrm{~m}\right)$, and the second stiffness ratio is $0.1\left(\alpha_{I}=0.1\right)$. The initial 
stiffness $k_{I}$ is adjusted so as to satisfy $T_{I}=2 \pi \sqrt{\left(m_{I}+\sum_{i=1}^{N} m_{i}\right) /\left(\alpha_{I} k_{I}\right)}=5.0 \mathrm{~s}$. The mass moment of inertia is $I_{I}=\pi r^{2} m_{I} / 12$, and $c_{I}=0$.

The mass of the base mat is $m_{0}=1.2 \times 10^{6} \mathrm{~kg}$, and the mass moment of inertia is $I_{0}=\pi r^{2} m_{0} / 12$. The radius of the equivalent circular rigid foundation is $r=\sqrt{400 / \pi} \mathrm{m}$. The swaying-rocking stiffnesses and damping coefficients of the spring-dashpot system for the equivalent circular rigid foundation are given as follows [32]:

$$
\begin{aligned}
& k_{H}=6.77 G r /(1.79-v), \quad k_{R}=2.52 G r^{3} /(1.00-v) \\
& c_{H}=6.21 \rho V_{s} r^{2} /(2.54-v), \quad c_{R}=0.136 \rho V_{s} r^{4} /(1.13-v)
\end{aligned}
$$

where $\rho, v, V_{s}$ denote the ground mass density, the Poisson's ratio, and the shear wave velocity, and $G=\rho V_{s}^{2}$ is the shear modulus. The numerical values $\rho=1.8 \times 10^{3} \mathrm{~kg} / \mathrm{m}^{3}$, $v=0.35$, and $V_{s}=200,133,100 \mathrm{~m} / \mathrm{s}$ are employed. Since $V_{s}=100 \mathrm{~m} / \mathrm{s}$ is rather flexible for base-isolated buildings, it is not recommended to build base-isolated buildings on the ground with $V_{s}=100 \mathrm{~m} / \mathrm{s}$.

Figure 4 shows the first to fourth undamped natural periods and the participation vectors of the non-isolated superstructure, the base-isolated building $\left(V_{s}=\infty\right)$, and the base-isolated buildings supported by swaying-rocking spring-dashpot systems $\left(V_{s}=200,133,100 \mathrm{~m} / \mathrm{s}\right)$. It is noted that the stiffness of the base-isolation story is given by the second stiffness because most of the response in the base-isolation story is in the second stiffness range, and the participation vectors are plotted in the $\mathbf{u}_{r}$ coordinate system. It can be observed that the ground stiffness does not prolong much of the fundamental natural period of the base-isolated building. It can also be observed that the value of the first to fourth participation vectors at the basement is quite small, and the values of much higher modes are almost one. This means that the responses of the fundamental mode and the higher mode are excited under the impulse input, although the response of the higher mode is hardly excited under the corresponding one-cycle sine wave. This higher mode leads to an excessive force response by the swaying spring and the swaying dashpot of the ground. However, the maximum responses of the base-isolation story and the superstructure are hardly affected because this higher mode response decreases soon.

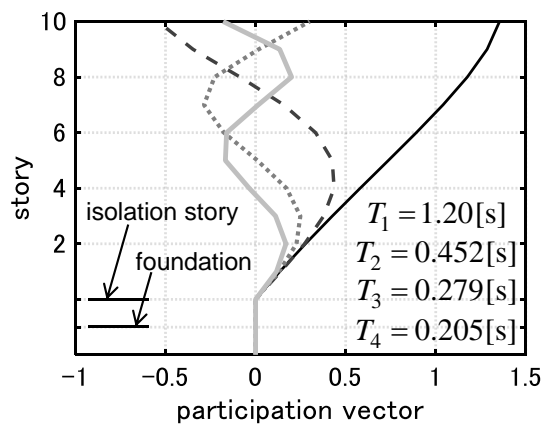

(a)

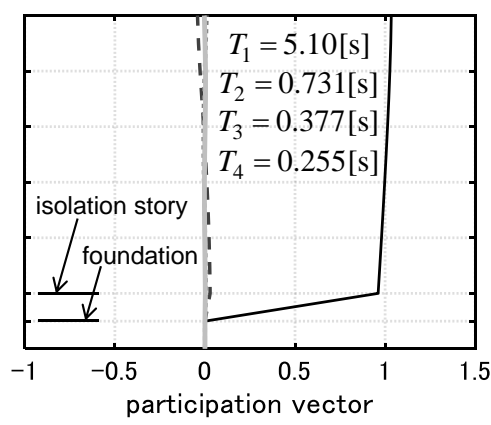

(b)

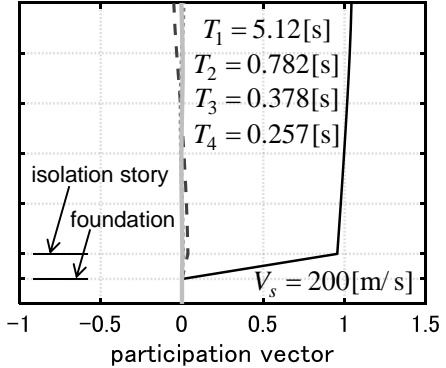

(c)

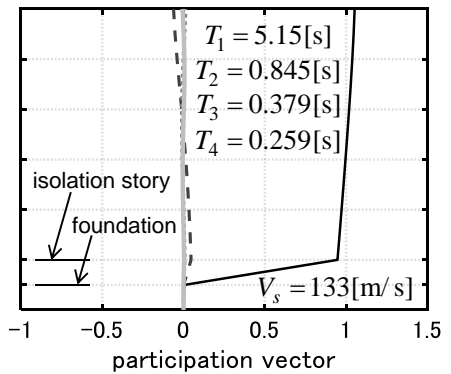

(d)

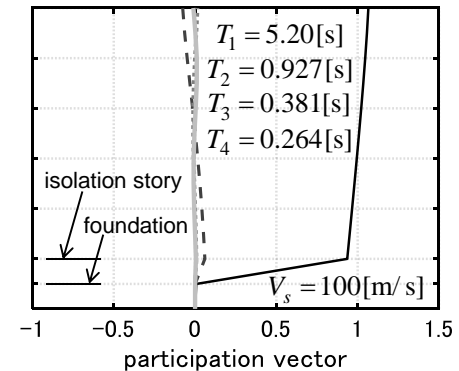

(e)

Figure 4. Undamped natural periods and participation vectors, (a) non-isolated superstructure, (b) base-isolated building $\left(V_{s}=\infty\right),(\mathbf{c}-\mathbf{e})$ base-isolated buildings supported by sway-rocking spring-dashpot system $\left(V_{s}=200,133,100[\mathrm{~m} / \mathrm{s}]\right)$. 


\subsection{Double Impulse}

Figures $5 \mathrm{a}, 6 \mathrm{a}, \mathrm{d}-8 \mathrm{a}$, d show the critical impulse timings of the base-isolated building $\left(V_{s}=\infty\right)$ and the base-isolated buildings supported by a sway-rocking spring-dashpot system $\left(V_{s}=200,133,100 \mathrm{~m} / \mathrm{s}\right)$. The input velocity of the double impulse is increased from $V=0.02 \mathrm{~m} / \mathrm{s}$ to $V=1.0 \mathrm{~m} / \mathrm{s}$ by $0.02 \mathrm{~m} / \mathrm{s}$. $t_{0}^{c, t o t a l}$ denotes the critical timing that maximizes the total input energy to the whole system, and $t_{0}^{c, S}$ denotes the critical timing that maximizes the instantaneous input energy to the base-isolated building, excluding the swaying-rocking spring-dashpot system of the ground. It is noted that these two types of critical timings are completely equivalent for the base-isolated building $\left(V_{s}=\infty\right)$. It can be observed that $t_{0}^{c, \text { total }}$ and $t_{0}^{c, S}$ are almost equal for various levels of the input velocities for all the models. This means that the total input energy to the whole system and the instantaneous input energy to the base-isolated building excluding the swaying-rocking spring-dashpot system are maximized at almost the same time.

Figures $5 \mathrm{~b}, 6 \mathrm{e}-8 \mathrm{e}$ show the time-history of $F_{I}=f_{I}+c_{I} \dot{u}_{I}$ for the models subjected to the first impulse with $V=0.5 \mathrm{~m} / \mathrm{s}$, and Figures $5 \mathrm{c}, 6 \mathrm{f}-8 \mathrm{f}$ present the time variations of $E_{2}^{S}$. It can be observed that $E_{2}^{S}$ is maximized when $F_{I}$ attains zero.

Figures $6 \mathrm{~b}-8 \mathrm{~b}$ show the time-history of $F_{s w a y}=k_{H} u_{0}+c_{H} \dot{u}_{0}$ for the models subjected to the first impulse with $V=0.5 \mathrm{~m} / \mathrm{s}$, and Figures $6 \mathrm{c}-8 \mathrm{c}$ present the time variations of $E_{2}$. It can be observed that $E_{2}$ is maximized when $F_{\text {sway }}$ attains zero. It is also noted that $F_{\text {sway }}$ becomes quite large just after the first impulse input. As stated in Section 5.2, the higher mode response is excited by the first impulse input, and the higher mode response decreases soon.

Hereafter, only $t_{0}^{c, S}$ is treated.

Figures 9-12 show the results of the time-history response analysis for the models under the critical double impulse. The input velocity of the double impulse is increased from $V=0.02 \mathrm{~m} / \mathrm{s}$ to $V=1.0 \mathrm{~m} / \mathrm{s}$ by $0.02 \mathrm{~m} / \mathrm{s}$. Figure 9 illustrates the distributions of the maximum interstory drifts of the superstructures, and Figure 10 presents the distributions of the maximum floor accelerations of the superstructures. Figure 11 indicates the maximum deformation of the base-isolation story, and Figure 12 shows the time-history of the top acceleration responses under the critical double impulse with $V=0.5 \mathrm{~m} / \mathrm{s}$. In Figures 9 and 10, the results under the critical double impulse with $V=0.1,0.2, \ldots, 1.0 \mathrm{~m} / \mathrm{s}$ are plotted. It is noted that retaining walls in the base-isolation story and the hardening of the base-isolated rubber bearings are not taken in account in this paper. Therefore, the input velocity levels should be $V \leq 0.5 \mathrm{~m} / \mathrm{s}$. However, the larger levels of the input velocity are treated for numerical investigations of soil-structure interaction with large deformation in the base-isolation story. It can be observed from Figure 11 that the ground stiffness hardly affects the maximum deformation in the base-isolation story. On the other hand, the decrease of the ground stiffness increases the responses of the superstructures a little. This is because the participation vectors of the second mode are slightly amplified by the decrease of the ground stiffness (Figure 4). Figure 12 also shows the slight amplification of the responses of the second mode.

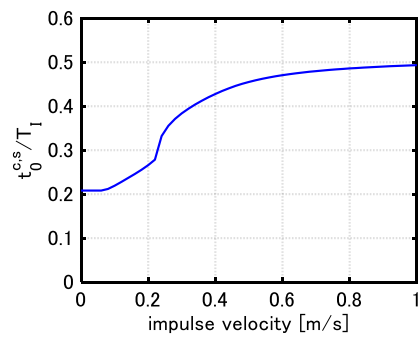

(a)

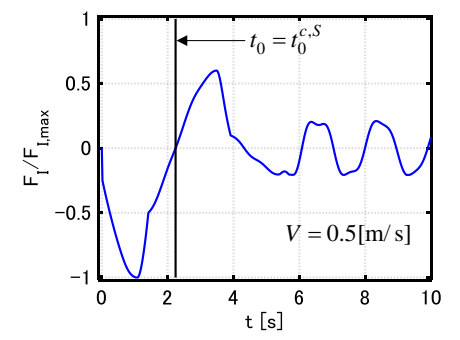

(b)

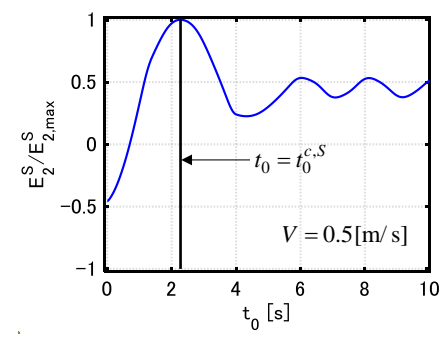

(c)

Figure 5. Critical impulse timing of base-isolated building $\left(V_{s}=\infty\right)$, (a) critical impulse timing $t_{0}^{c, S}$, (b) time-history of $F_{I}=f_{I}+c_{I} \dot{u}_{I}$ subjected to first single impulse with $V=0.5[\mathrm{~m} / \mathrm{s}],(\mathrm{c})$ time variation of $E_{2}^{S}$. 


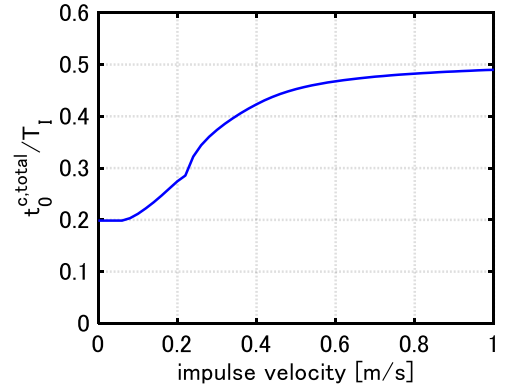

(a)

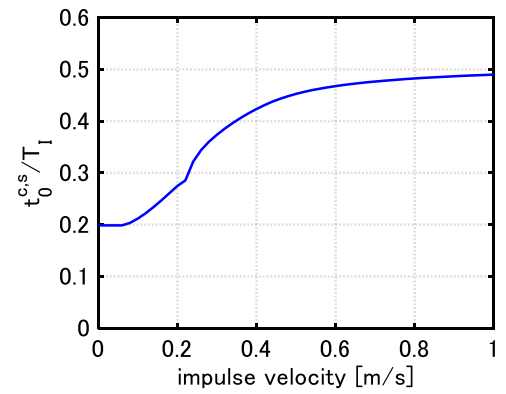

(d)

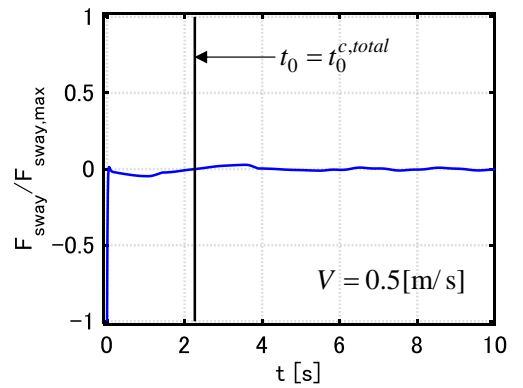

(b)

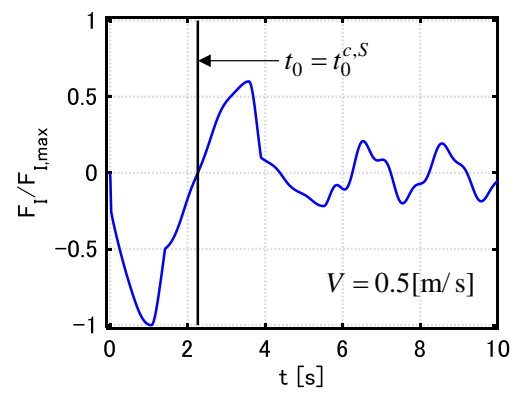

(e)

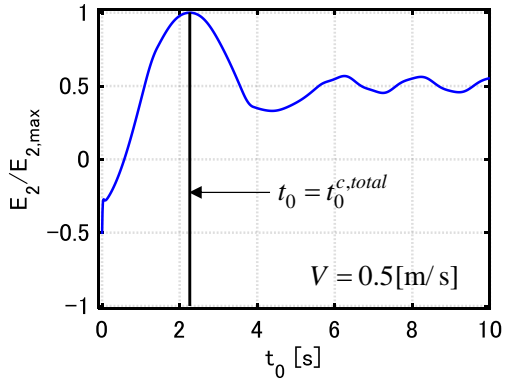

(c)

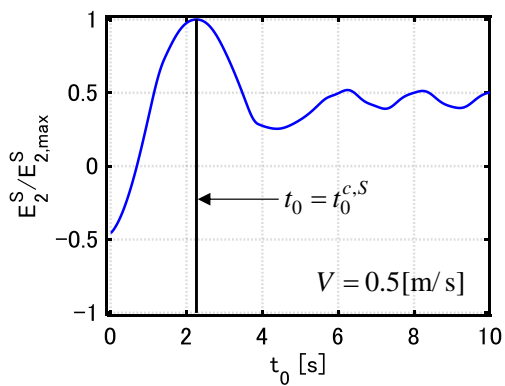

(f)

Figure 6. Critical impulse timings of base-isolated building supported by swaying-rocking spring-dashpot system $\left(V_{s}=200[\mathrm{~m} / \mathrm{s}]\right),(\mathbf{a})$ critical impulse timing $t_{0}^{c, t o t a l},(\mathbf{b})$ time-history of $F_{s w a y}=k_{H} u_{0}+c_{H} \dot{u}_{0}$ subjected to first single impulse with $V=0.5[\mathrm{~m} / \mathrm{s}],(\mathbf{c})$ time variation of $E_{2},(\mathbf{d})$ critical impulse timing $t_{0}^{c, S},(\mathbf{e})$ time-history of $F_{I}=f_{I}+c_{I} \dot{u}_{I}$ subjected to first single impulse with $V=0.5[\mathrm{~m} / \mathrm{s}]$, (f) time variation of $E_{2}^{S}$.



(a)

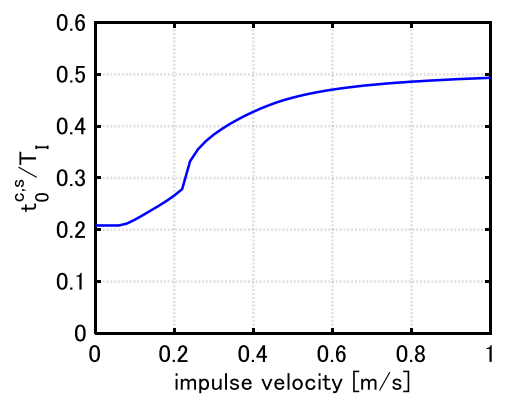

(d)

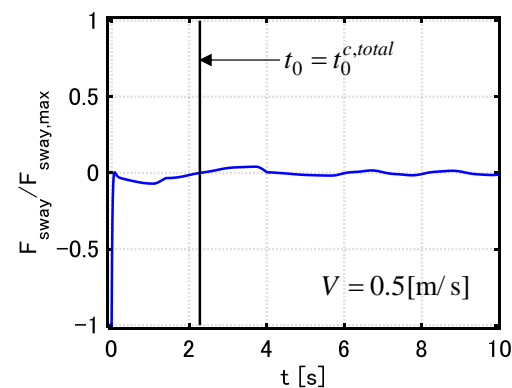

(b)

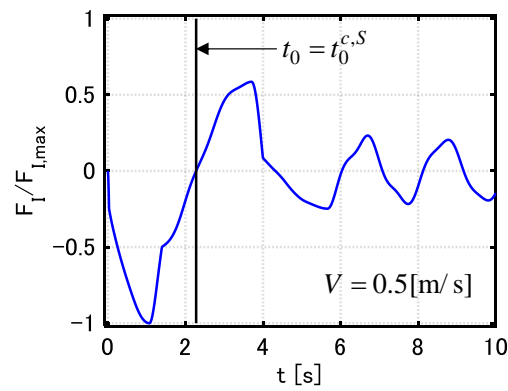

(e)

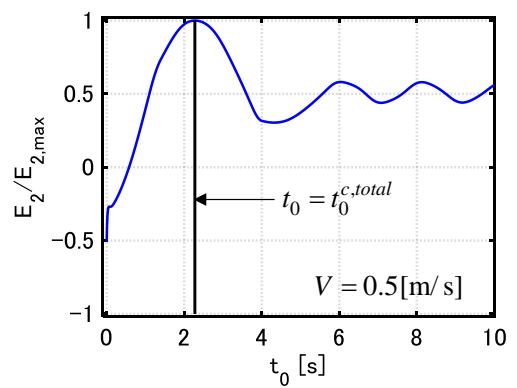

(c)

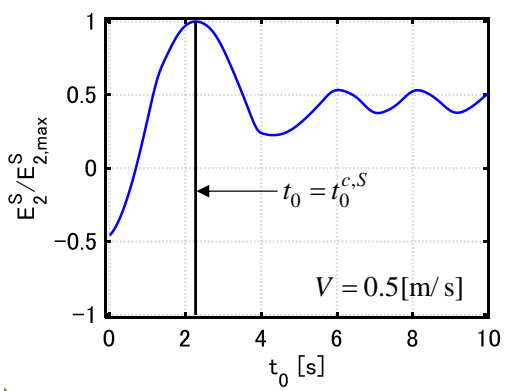

(f)

Figure 7. Critical impulse timings of base-isolated building supported by swaying-rocking spring-dashpot system $\left(V_{s}=133[\mathrm{~m} / \mathrm{s}]\right),(\mathbf{a})$ critical impulse timing $t_{0}^{c, t o t a l},(\mathbf{b})$ time-history of $F_{\text {sway }}=k_{H} u_{0}+c_{H} \dot{u}_{0}$ subjected to first single impulse with $V=0.5[\mathrm{~m} / \mathrm{s}],(\mathbf{c})$ time variation of $E_{2},(\mathbf{d})$ critical impulse timing $t_{0}^{c, S},(\mathbf{e})$ time-history of $F_{I}=f_{I}+c_{I} \dot{u}_{I}$ subjected to first single impulse with $V=0.5[\mathrm{~m} / \mathrm{s}],(\mathbf{f})$ time variation of $E_{2}^{S}$. 


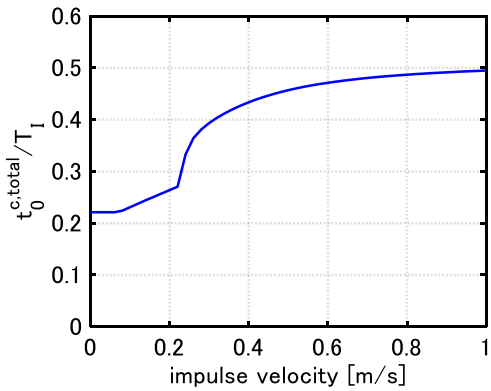

(a)

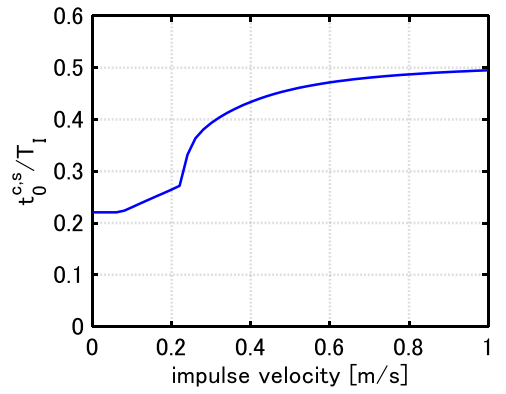

(d)

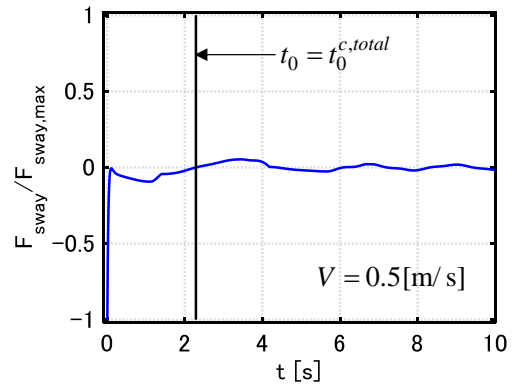

(b)

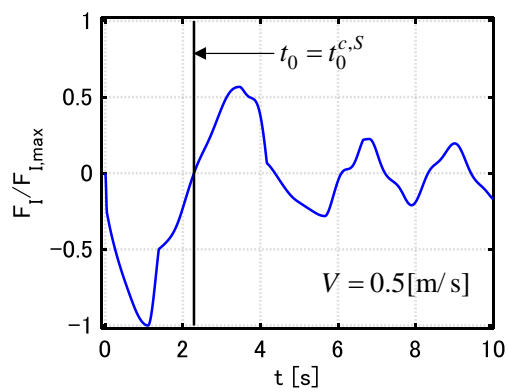

(e)

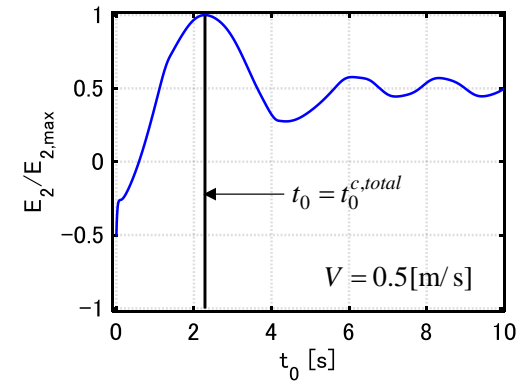

(c)

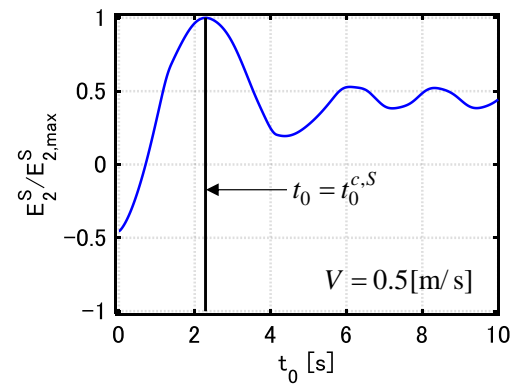

(f)

Figure 8. Critical impulse timings of base-isolated building supported by swaying-rocking spring-dashpot system $\left(V_{s}=100[\mathrm{~m} / \mathrm{s}]\right),(\mathbf{a})$ critical impulse timing $t_{0}^{c, t o t a l},(\mathbf{b})$ time-history of $F_{\text {sway }}=k_{H} u_{0}+c_{H} \dot{u}_{0}$ subjected to first single impulse with $V=0.5[\mathrm{~m} / \mathrm{s}],(\mathbf{c})$ time variation of $E_{2},(\mathbf{d})$ critical impulse timing $t_{0}^{c, S},(\mathbf{e})$ time-history of $F_{I}=f_{I}+c_{I} \dot{u}_{I}$ subjected to first single impulse with $V=0.5[\mathrm{~m} / \mathrm{s}],(\mathbf{f})$ time variation of $E_{2}^{S}$.

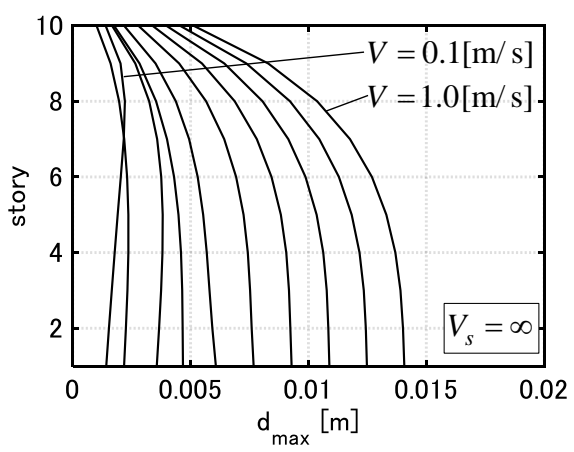

(a)

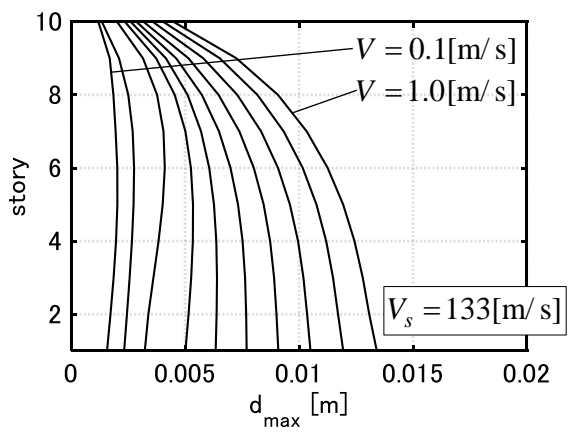

(c)

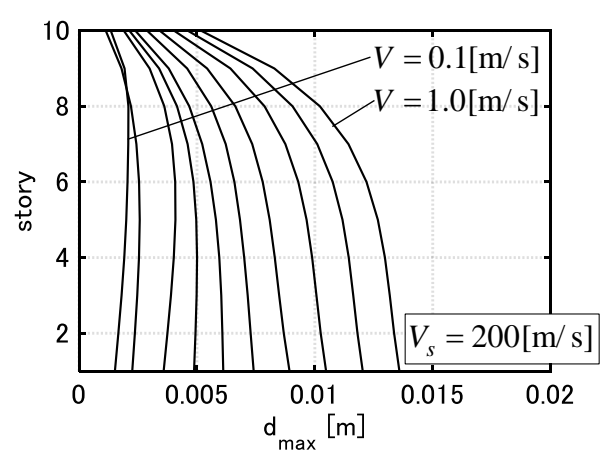

(b)

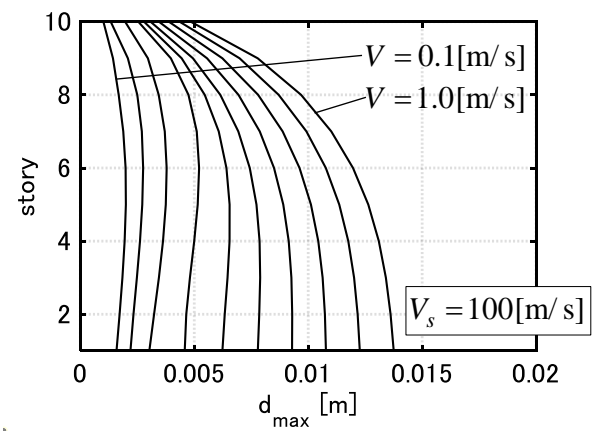

(d)

Figure 9. Distributions of maximum interstory drifts of superstructure under critical double impulse, (a) $V_{s}=\infty,(\mathbf{b}) V_{s}=200[\mathrm{~m} / \mathrm{s}],(\mathbf{c}) V_{s}=133[\mathrm{~m} / \mathrm{s}]$, (d) $V_{s}=100[\mathrm{~m} / \mathrm{s}]$. 


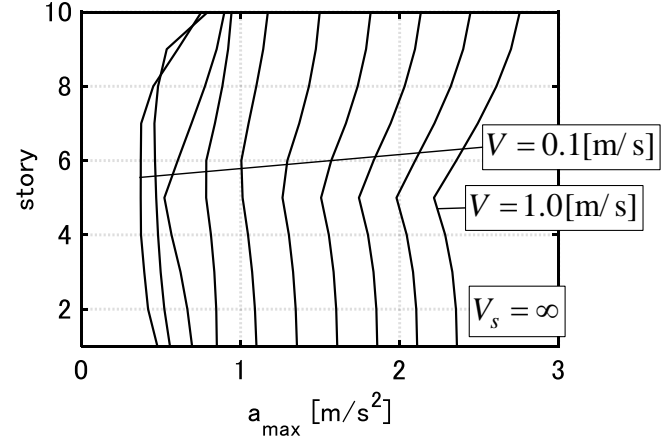

(a)

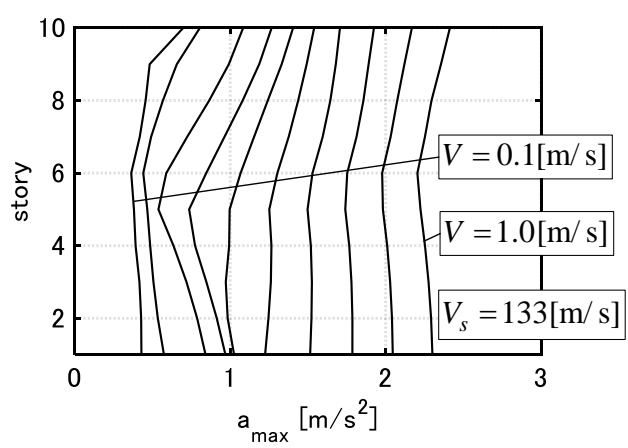

(c)

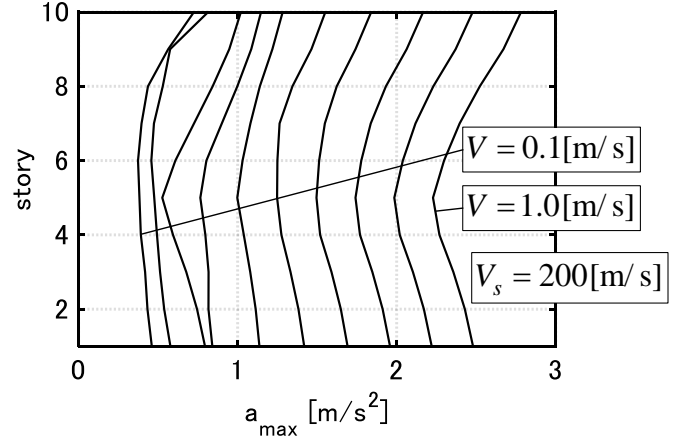

(b)

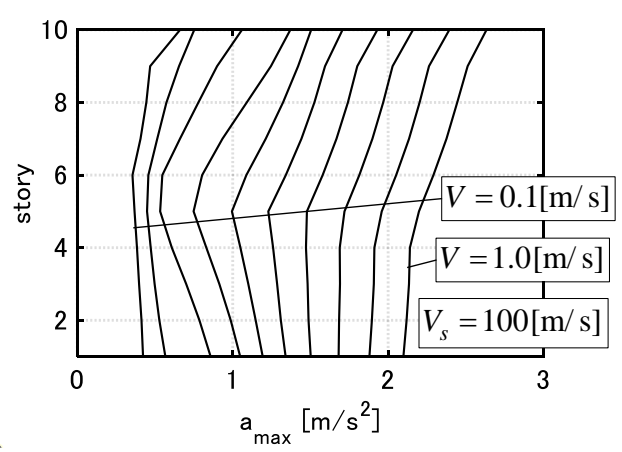

(d)

Figure 10. Distributions of maximum floor accelerations of superstructure under critical double impulse, (a) $V_{s}=\infty,(\mathbf{b}) V_{s}=200[\mathrm{~m} / \mathrm{s}]$, (c) $V_{s}=133[\mathrm{~m} / \mathrm{s}],(\mathbf{d}) V_{s}=100[\mathrm{~m} / \mathrm{s}]$.

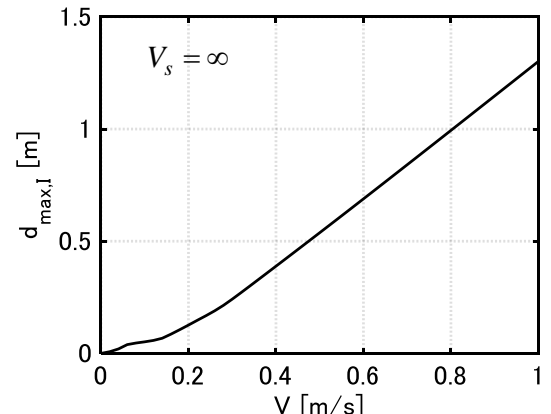

(a)

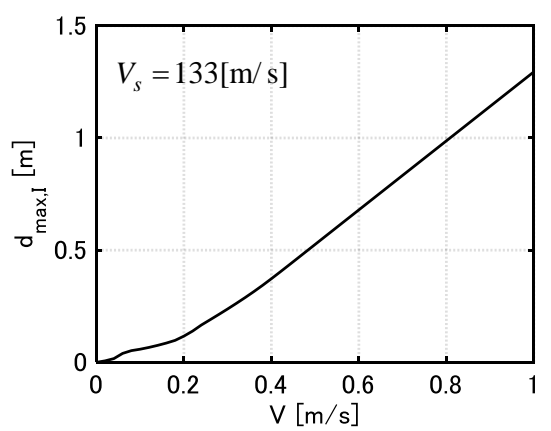

(c)

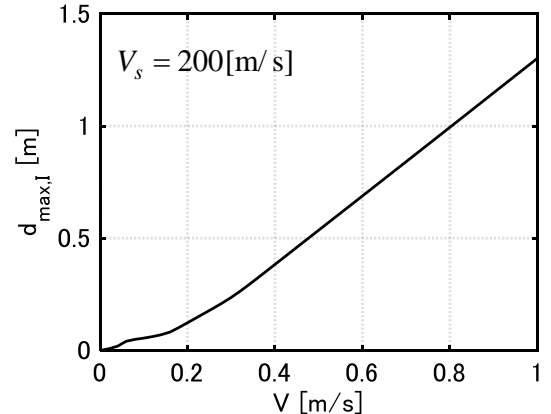

(b)

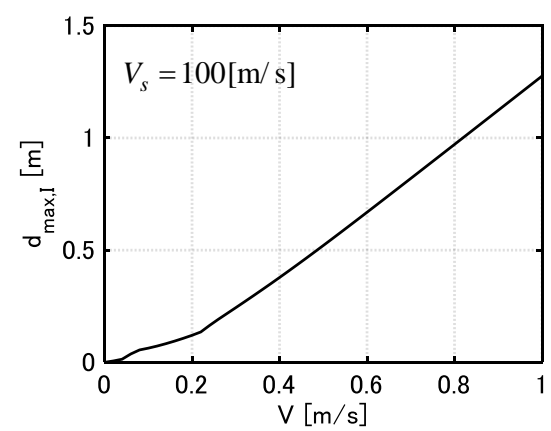

(d)

Figure 11. Maximum deformation of base-isolation story under critical double impulse, (a) $V_{s}=\infty$, (b) $V_{s}=200[\mathrm{~m} / \mathrm{s}]$, (c) $V_{s}=133[\mathrm{~m} / \mathrm{s}]$, (d) $V_{s}=100[\mathrm{~m} / \mathrm{s}]$. 


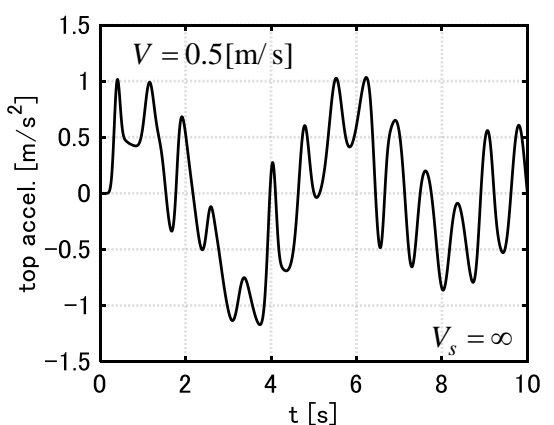

(a)

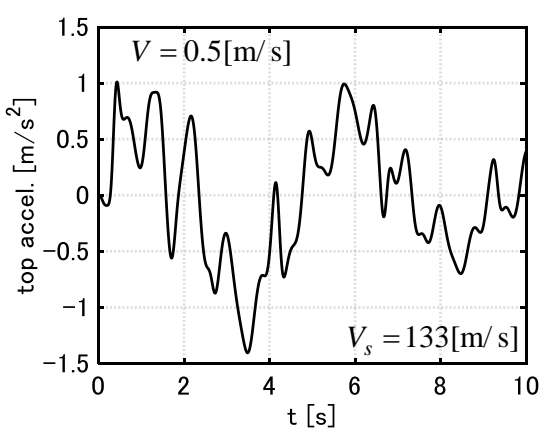

(c)

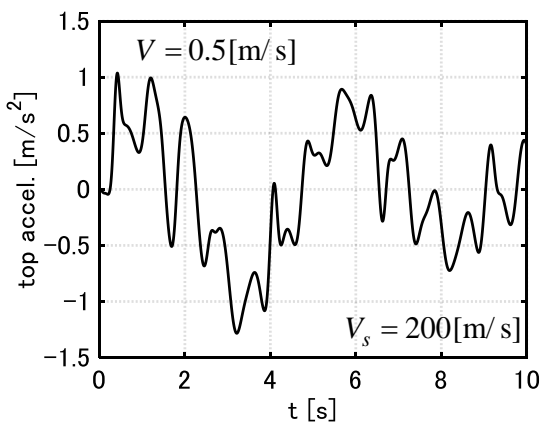

(b)

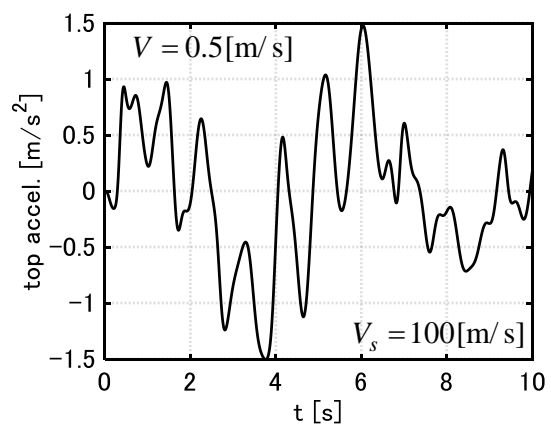

(d)

Figure 12. Time-history of top floor accelerations under critical double impulse with $V=0.5[\mathrm{~m} / \mathrm{s}]$, (b) $V_{s}=200[\mathrm{~m} / \mathrm{s}],(\mathbf{c}) V_{s}=133[\mathrm{~m} / \mathrm{s}]$, (d) $V_{s}=100[\mathrm{~m} / \mathrm{s}]$.

\subsection{One-Cycle Sine Wave}

Figures 13-16 show the results of the time-history response analysis for the models under the corresponding one-cycle sine wave. Figure 13 illustrates the distributions of the maximum interstory drifts of the superstructures, and Figure 14 presents the distributions of the maximum floor accelerations of the superstructures. Figure 15 indicates the maximum deformation in the base-isolation story, and Figure 16 shows the time-history of the top acceleration responses under the corresponding one-cycle sine wave with $V=0.5 \mathrm{~m} / \mathrm{s}$. It can be observed from these figures that, as in the cases of the critical double impulse, the ground stiffness hardly affects the maximum deformation in the base-isolation story, and the decrease of the ground stiffness increases the responses of the superstructures a little. The maximum responses under the critical double impulse are about 1.1 times larger than those under the corresponding one-cycle sine wave.

Figure 17 shows the comparison of the time-history of the deformation and the restoring force in the base-isolation story under the critical double impulse with $V=0.5 \mathrm{~m} / \mathrm{s}$ and the corresponding one-cycle sine wave. The force-deformation relations are also illustrated. It can be observed that the responses under the critical double impulse and the corresponding one-cycle sine wave correspond well. 


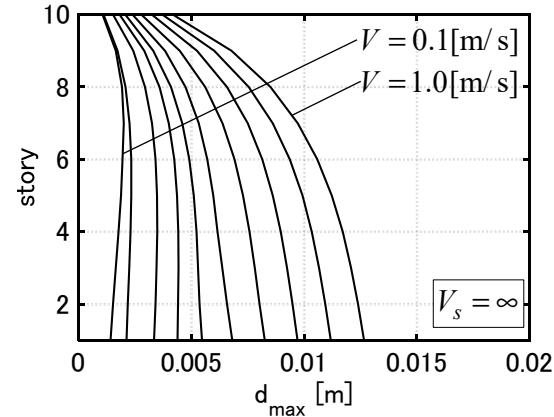

(a)

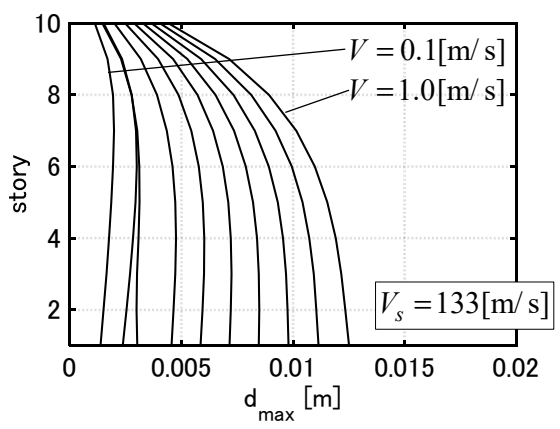

(c)

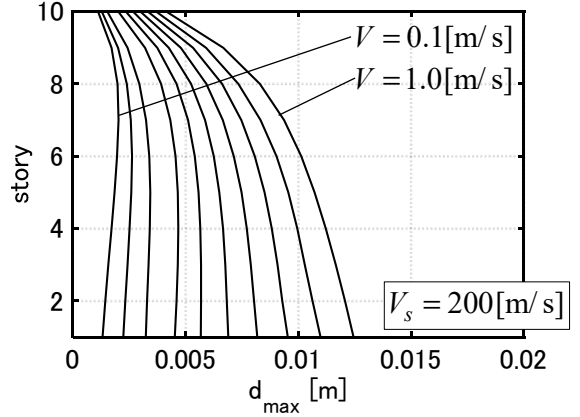

(b)

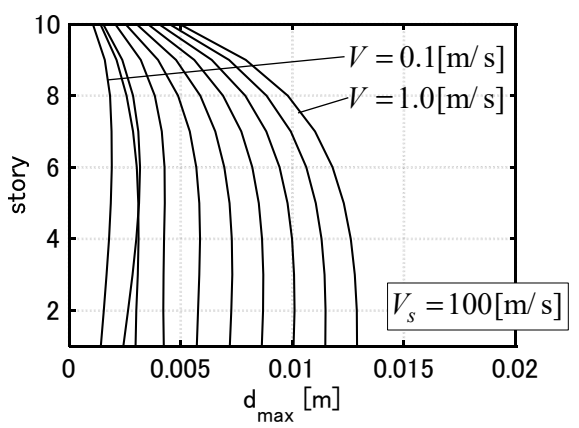

(d)

Figure 13. Distributions of maximum interstory drifts of superstructure under corresponding onecycle sine wave, $(\mathbf{a}) V_{s}=\infty,(\mathbf{b}) V_{s}=200[\mathrm{~m} / \mathrm{s}],(\mathbf{c}) V_{s}=133[\mathrm{~m} / \mathrm{s}],(\mathbf{d}) V_{s}=100[\mathrm{~m} / \mathrm{s}]$.

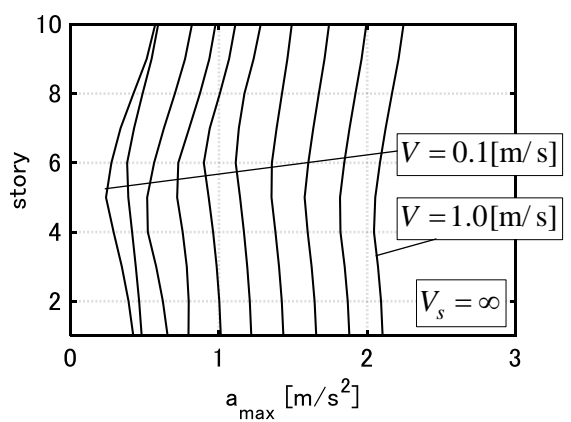

(a)

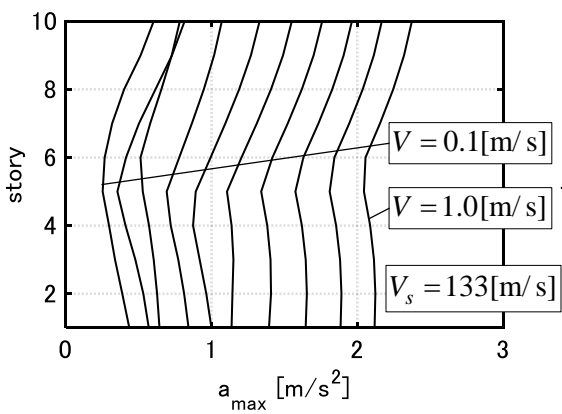

(c)

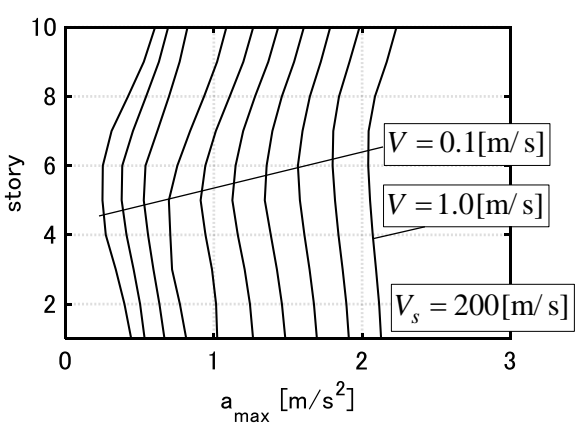

(b)

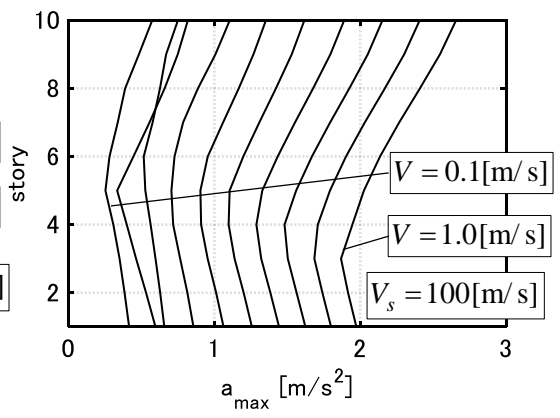

(d)

Figure 14. Distributions of maximum floor accelerations of superstructure under corresponding one-cycle sine wave, (a) $V_{s}=\infty,(\mathbf{b}) V_{s}=200[\mathrm{~m} / \mathrm{s}]$, (c) $V_{s}=133[\mathrm{~m} / \mathrm{s}]$, (d) $V_{s}=100[\mathrm{~m} / \mathrm{s}]$. 


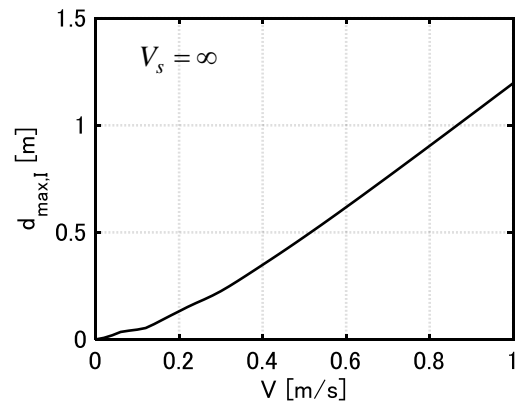

(a)

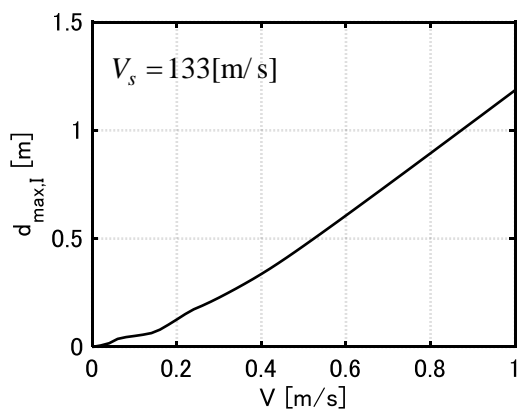

(c)

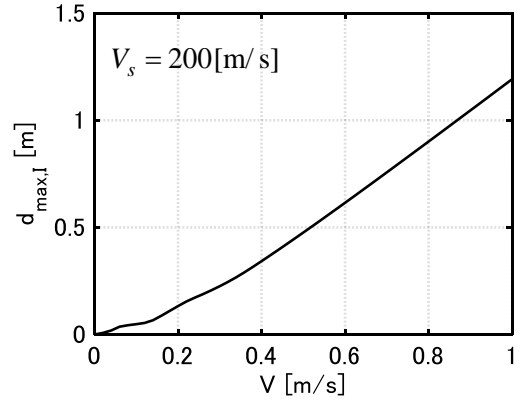

(b)

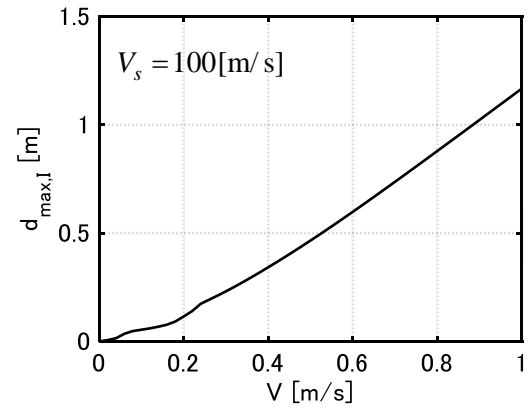

(d)

Figure 15. Maximum deformation of base-isolation story under corresponding one-cycle sine wave, (a) $V_{s}=\infty,(\mathbf{b}) V_{s}=200[\mathrm{~m} / \mathrm{s}]$, (c) $V_{s}=133[\mathrm{~m} / \mathrm{s}]$, (d) $V_{s}=100[\mathrm{~m} / \mathrm{s}]$.

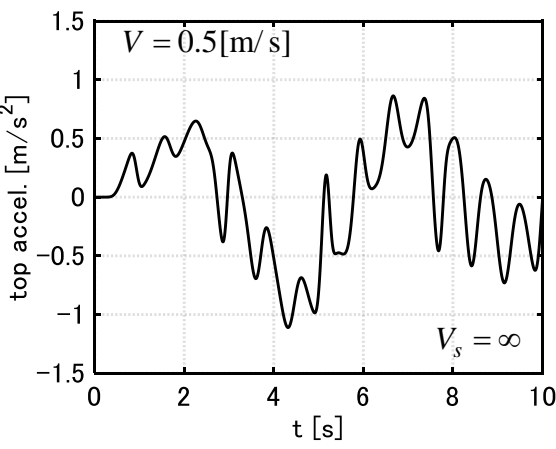

(a)

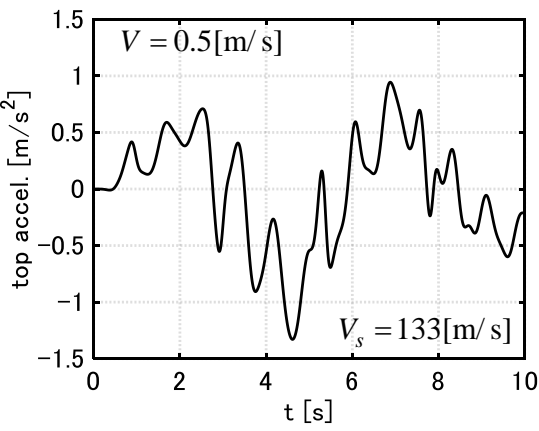

(c)

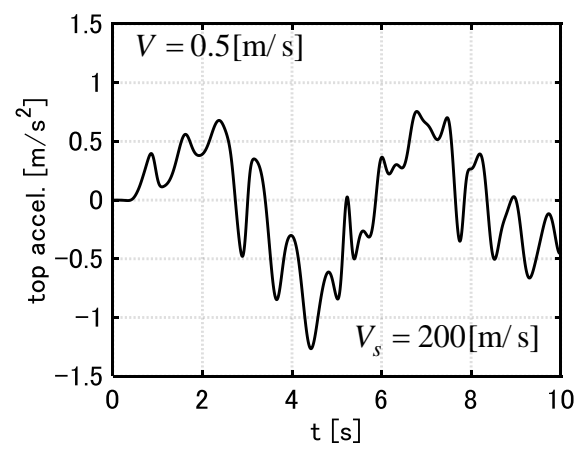

(b)

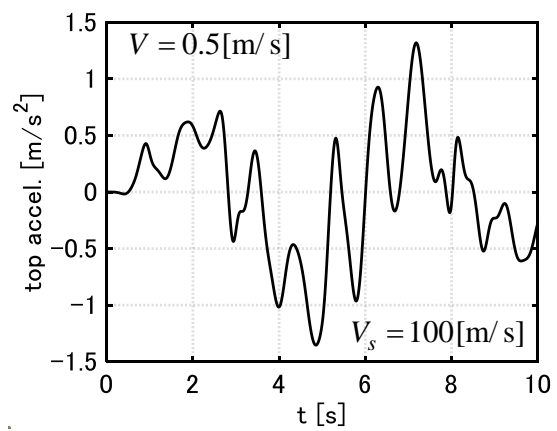

(d)

Figure 16. Time-history of top floor accelerations under corresponding one-cycle sine wave with $V=0.5[\mathrm{~m} / \mathrm{s}]$, (a) $V_{s}=\infty,(\mathbf{b}) V_{s}=200[\mathrm{~m} / \mathrm{s}],(\mathbf{c}) V_{s}=133[\mathrm{~m} / \mathrm{s}],(\mathbf{d}) V_{s}=100[\mathrm{~m} / \mathrm{s}]$. 

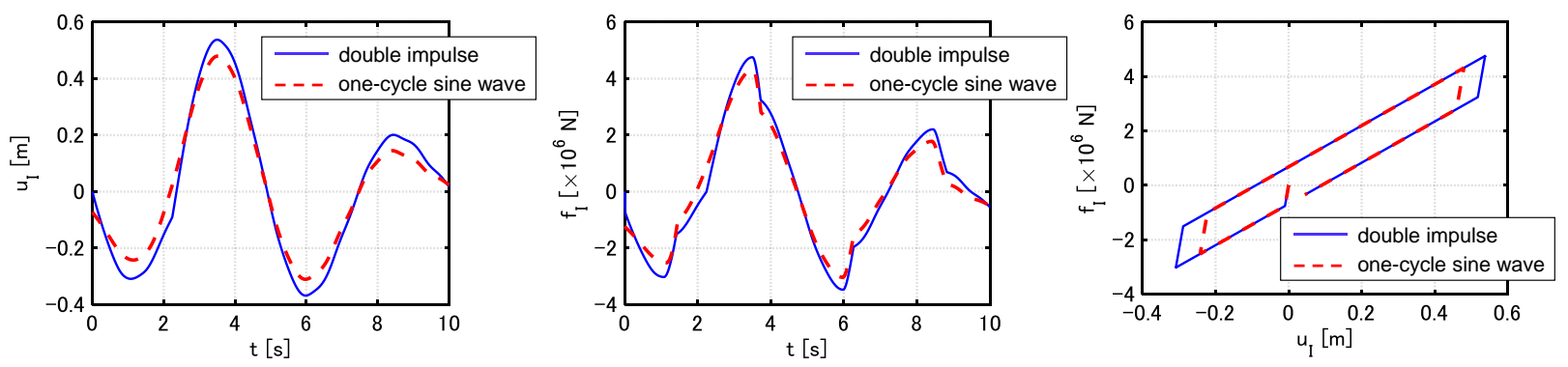

(a)
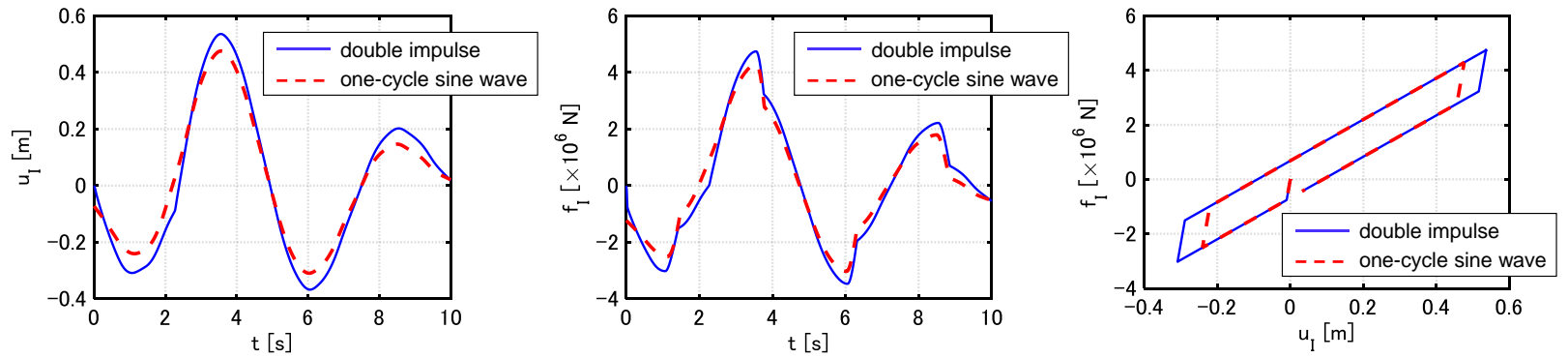

(b)
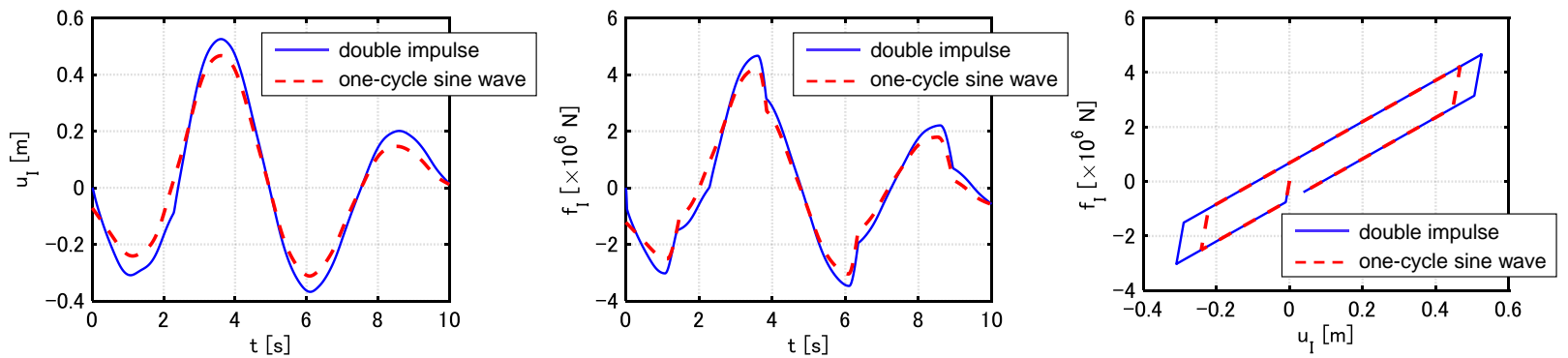

(c)
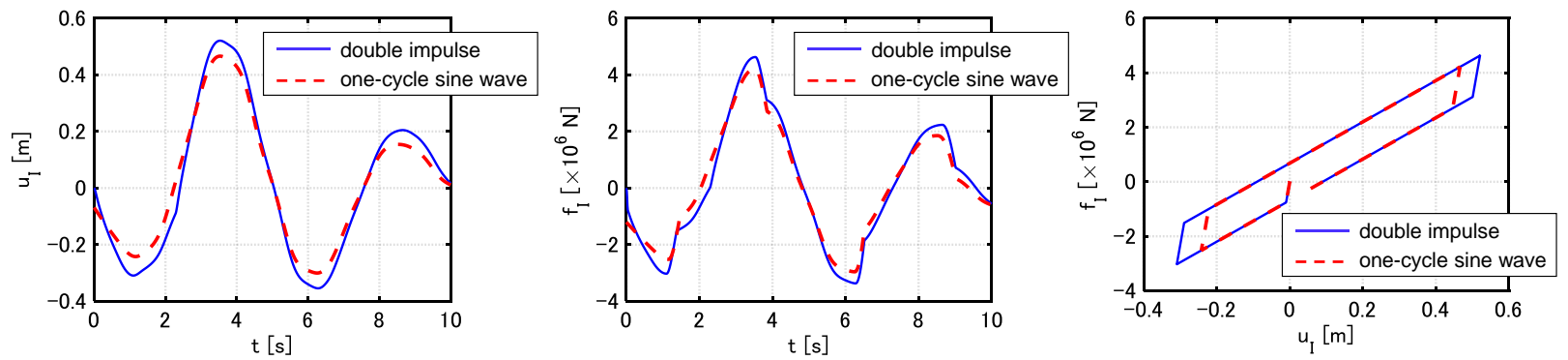

(d)

Figure 17. Time histories of base-isolation story deformation and restoring-force and force-deformation relation under critical double impulse with $V=0.5[\mathrm{~m} / \mathrm{s}]$ and corresponding one-cycle sine wave, (a) $V_{s}=\infty,(\mathbf{b}) V_{s}=200[\mathrm{~m} / \mathrm{s}]$, (c) $V_{s}=133[\mathrm{~m} / \mathrm{s}],(\mathbf{d}) V_{s}=100[\mathrm{~m} / \mathrm{s}]$.

\section{Soil-Structure Interaction under Long-Duration Ground Motions}

In this section, the time-history response analysis under the critical multi impulse is conducted. It is well-known that base-isolated buildings are vulnerable for long-period, long-duration ground motions. The effect of the soil-structure interaction on the maximum responses of the base-isolated building is examined.

A multi impulse (Figure 18) is employed to simulate the critical responses of the baseisolated buildings under long-period, long-duration ground motions [24,33]. A multi-cycle sine wave is another substitute of long-duration motions. The use of the multi impulse provides the critical input period for elastic-plastic MDOF models without repetition. This 
is because the critical condition of the impulse inputs shown in Section 4 is applicable to the case of the multi impulse. In the case of the multi-cycle sine wave, an iterative procedure with much computational effort is required to obtain the critical responses of the elastic-plastic MDOF models by parametrically changing the input period.

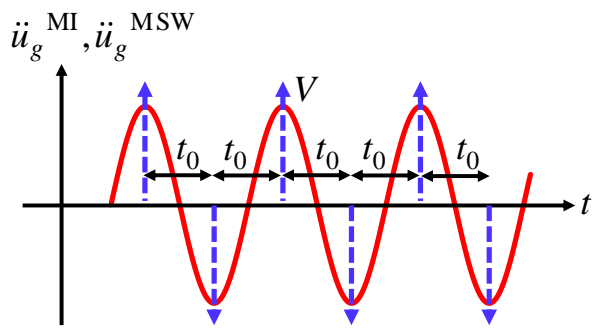

Figure 18. Multi impulse as substitute of long-duration ground motion.

To find the critical impulse timing of the multi impulse, each time interval of two consecutive impulse inputs is changed repeatedly so that each impulse input meets the critical condition. This procedure is repeated until the time interval converges. Then the time-history response analysis under the multi impulse with the constant time interval (the convergence value of the time interval) is conducted and whether the impulse input meets the critical condition in the steady-state response is checked.

Figure 19 shows the results of the time-history response analysis under the critical multi impulse with $V=0.21 \mathrm{~m} / \mathrm{s}$ for the base-isolated building $\left(V_{s}=\infty\right)$ and the baseisolated buildings supported by a swaying-rocking spring-dashpot system $\left(V_{s}=133 \mathrm{~m} / \mathrm{s}\right)$. It can be observed that the maximum deformation in the base-isolation story of the baseisolated building supported by the swaying-rocking spring-dashpot system $\left(V_{s}=133 \mathrm{~m} / \mathrm{s}\right)$ is about 1.4 times larger than that of the base-isolated building on the rigid ground $\left(V_{s}=\infty\right)$. The decrease of the ground stiffness increases the hysteretic energy of the swaying-rocking spring in the steady state response slightly, and the stored hysteretic energy increases the kinetic energy of the whole system at the timing just before the impulse input. In other words, when the whole system exhibits resonant responses, the input to the base-isolated building by the base mat is amplified. Unlike the cases of the double impulse, the effect of soil-structure interaction is not negligible.

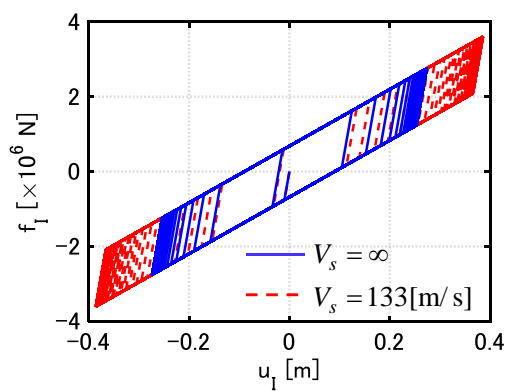

(a)

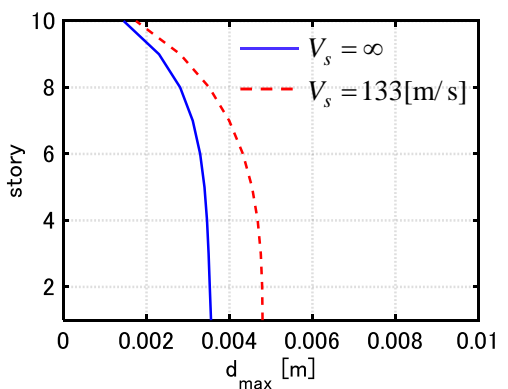

(b)

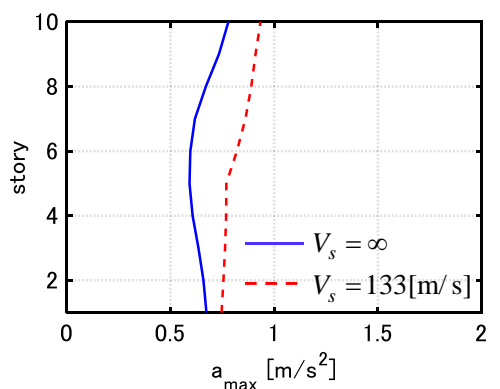

(c)

Figure 19. Responses of base-isolated building $\left(V_{s}=\infty\right)$ and base-isolated building supported by swaying-rocking spring-dashpot system $\left(V_{s}=133[\mathrm{~m} / \mathrm{s}]\right)$ under critical multi impulse with $V=0.21[\mathrm{~m} / \mathrm{s}],(\mathbf{a})$ force-deformation relation of base-isolation story, (b) distributions of maximum interstory drifts of superstructure, (c) distributions of maximum floor accelerations of superstructure.

\section{Discussion}

In this section, the results of the numerical examples presented in previous sections are summarized and discussed. 
The ground stiffness hardly affects the maximum deformation of the base-isolation story under the critical double impulse. On the other hand, the decrease of the ground stiffness increases the responses of the superstructures a little. This is because the participation vector of the second mode is slightly amplified by the decrease of the ground stiffness. As in the cases of the double impulse, the ground stiffness hardly affects the maxi-mum deformation of the base-isolation story under the one-cycle sine wave, and the decrease of the ground stiffness increases the responses of the superstructures a little.

In the case of the ground motions with short duration such as the above-mentioned motions, the effect of soil-structure interaction is not significant. However, the effect of soil-structure interaction is not negligible in the case of the critical multi impulse. In particular, the maximum deformation in the base-isolation story may be enlarged by the decrease of the ground stiffness.

The duration of ground motion plays a key role in the critical responses of baseisolated buildings on flexible ground. The soil-structure interaction has negative effects on the maximum responses of base-isolated buildings under long-duration ground motions, although it has slightly negative effects under short-duration motions.

\section{Conclusions}

In this paper, the critical responses were clarified for nonlinear base-isolated buildings considering soil-structure interaction under the double impulse and the multi impulse. The main conclusions can be summarized as follows.

1. A one-cycle sine wave and a double impulse effectively express a main characteristic of a fling-step motion. The use of the double impulse enables the capturing of the critical input period for elastic-plastic MDOF models without repetition. On the other hand, in the case of the one-cycle sine wave, an iterative procedure with much computational effort is required to obtain the critical responses of the elastic-plastic MDOF models by parametrically changing the input period.

2. The critical impulse timing was derived that maximizes the total input energy to the whole system for MDOF building models supported by a swaying-rocking springdashpot system. The maximization of the total input energy is equal to the maximization of the input energy by the second impulse. The critical condition is that the sum of the forces by the swaying spring-dashpot of the ground after the first impulse is equal to zero.

3. Another type of the critical impulse timing was derived that maximizes the instantaneous input energy to a base-isolated building excluding the swaying-rocking system. The critical condition is that the sum of the forces by the restoring force and the damping force of the base-isolation story after the first impulse is equal to zero. The two types of critical timings were shown to be almost equal. This means that the total input energy to the whole system and the instantaneous input energy to the base-isolated building excluding the swaying-rocking spring-dashpot system are maximized at almost the same time.

4. The maximum responses under the critical double impulse are about 1.1 times larger than those under the corresponding one-cycle sine wave. Moreover, the time-history of the deformation and the restoring force of the base-isolation story under the critical double impulse and the corresponding one-cycle sine wave correspond well. Therefore, the critical double impulse works well to simulate the critical responses under the one-cycle sine wave.

5. The multi impulse was employed to simulate the critical response of a base-isolated buildings supported by a swaying-rocking spring-dashpot system under long-duration ground motions.

6. The duration of ground motion plays a key role in the critical responses of baseisolated buildings on flexible ground. The soil-structure interaction has negative effects on the maximum responses of base-isolated buildings under long-duration 
ground motions, although it has slightly negative effects under short-duration motions.

Author Contributions: Conceptualization, H.A. and I.T.; methodology, H.A. and I.T.; software, H.A.; validation, H.A. and I.T.; formal analysis, H.A.; investigation, H.A. and I.T.; resources, H.A. and I.T.; data curation, H.A. and I.T.; writing-original draft preparation, H.A.; writing-review and editing, I.T.; visualization, H.A.; supervision, I.T.; project administration, H.A. and I.T.; funding acquisition, H.A. and I.T. Both authors have read and agreed to the published version of the manuscript.

Funding: This research was funded by the Grant-in-Aid for Scientific Research (KAKENHI) of Japan Society for the Promotion of Science, grant number 18H01584, JP20J20811. This support is greatly appreciated.

Conflicts of Interest: The authors declare no conflict of interest.

\section{References}

1. Kelly, J.M.; Konstantinidis, D. Mechanics of Rubber Bearings for Seismic and Vibration Isolation; Wiley: Chichester, UK, 2011; Volume 222.

2. Lagaros, N.D. (Ed.) Design Optimization of Active and Passive Structural Control Systems; IGI Global: Hershey, PA, USA, 2012.

3. Takewaki, I.; Akehashi, H. Comprehensive review of optimal and smart design of nonlinear building structures with and without passive dampers subjected to earthquake loading. Front. Built Environ. 2021, 7, 211. [CrossRef]

4. Matsagar, V.A.; Jangid, R.S. Base isolation for seismic retrofitting of structures. Pract. Period. Struct. Des. Constr. 2008, 13, 175-185. [CrossRef]

5. Jangid, R.S.; Kelly, J.M. Base isolation for near-fault motions. Earthq. Eng. Struct. Dyn. 2001, 30, 691-707. [CrossRef]

6. Tsai, H.C.; Kelly, J.M. Seismic response of heavily damped base isolation systems. Earthq. Eng. Struct. Dyn. 1993, 22, 633-645. [CrossRef]

7. Hall, J.F.; Heaton, T.H.; Halling, M.W.; Wald, D.J. Near-source ground motion and its effects on flexible buildings. Earthq. Spectra 1995, 11, 569-605. [CrossRef]

8. Lou, M.; Wang, H.; Chen, X.; Zhai, Y. Structure-soil-structure interaction: Literature review. Soil Dyn. Earthq. Eng. 2011, 31, 1724-1731. [CrossRef]

9. Wolf, J.P. Soil-structure-interaction analysis in time domain. In Structural Mechanics in Reactor Technology; Electrowatt Engineering Services Ltd.: Zurich, Switzerland, 1987.

10. Gazetas, G.; Mylonakis, G. Soil-structure interaction effects on elastic and inelastic structures. In Proceedings of the International Conferences on Recent Advances in Geotechnical Earthquake Engineering and Soil Dynamics, San Diego, CA, USA, 26-31 March 2001; Volume 3.

11. Mylonakis, G.; Gazetas, G. Seismic soil-structure interaction: Beneficial or detrimental? J. Earthq. Eng. 2000, 4, 277-301. [CrossRef]

12. Takewaki, I. Equivalent linear ductility design of soil-structure interaction systems. Eng. Struct. 1998, 20, 655-662. [CrossRef]

13. Takewaki, I. Probabilistic critical excitation for MDOF elastic-plastic structures on compliant ground. Earthq. Eng. Struct. Dyn. 2001, 30, 1345-1360. [CrossRef]

14. Takewaki, I.; Murakami, S.; Fujita, K.; Yoshitomi, S.; Tsuji, M. The 2011 off the Pacific coast of Tohoku earthquake and response of high-rise buildings under long-period ground motions. Soil Dyn. Earthq. Eng. 2011, 31, 1511-1528. [CrossRef]

15. Garevski, M.; Gjorgiev, I.; Edip, K.; Sesov, V.; Cvetanovska, J. Effects of soil medium on response of base isolated multistory frame structures. In Proceedings of the 15th World Conference on. Earthquake Engineering 2012, (15WCEE), Lisbon, Portugal, 24-28 September 2012.

16. Haiyang, Z.; Xu, Y.; Chao, Z.; Dandan, J. Shaking table tests for the seismic response of a base-isolated structure with the SSI effect. Soil Dyn. Earthq. Eng. 2014, 67, 208-218. [CrossRef]

17. Novak, M.; Henderson, P. Base-isolated buildings with soil-structure interaction. Earthq. Eng. Struct. Dyn. 1989, 18, 751-765. [CrossRef]

18. Spyrakos, C.C.; Maniatakis, C.A.; Koutromanos, I.A. Soil-structure interaction effects on base-isolated buildings founded on soil stratum. Eng. Struct. 2009, 31, 729-737. [CrossRef]

19. Tongaonkar, N.; Jandid, R. Seismic response of isolated bridges with soil-structure interaction. Soil Dyn. Earthq. Eng. 2003, 23, 287-302. [CrossRef]

20. Forcellini, D. Cost assessment of isolation technique applied to a benchmark bridge with soil structure interaction. Bull. Earthq. Eng. 2016, 15, 51-69. [CrossRef]

21. Forcellini, D. Seismic assessment of a benchmark based isolated ordinary building with soil structure interaction. Bull. Earthq. Eng. 2017, 16, 2021-2042. [CrossRef]

22. Luco, J.E. Effects of soil-structure interaction on seismic base isolation. Soil Dyn. Earthq. Eng. 2014, 66, 167-177. [CrossRef]

23. Akehashi, H.; Kojima, K.; Fujita, K.; Takewaki, I. Critical response of nonlinear base-isolated building considering soil-structure interaction under double impulse as substitute for near-fault ground motion. Front. Built Environ. 2018, 4, 34. [CrossRef] 
24. Akehashi, H.; Takewaki, I. Critical response of nonlinear base-isolated building considering soil-structure interaction. In Proceedings of the 17th World Conference on Earthquake Engineering 2020, 17WCEE, Sendai, Japan, 13-18 September 2020.

25. Skinner, R.I.; Robinson, W.H.; McVerry, G.H. An Introduction to Seismic Isolation; Wiley: Hoboken, NJ, USA, 1993.

26. Hayden, C.P.; Bray, J.D.; Abrahamson, N.A. Selection of near-fault pulse motions. J. Geotech. Geoenviron. Eng. 2014, 140, 04014030. [CrossRef]

27. Kalkan, E.; Kunnath, S.K. Effects of fling step and forward directivity on seismic response of buildings. Earthq. Spectra 2006, 22, 367-390. [CrossRef]

28. Kojima, K.; Takewaki, I. Critical earthquake response of elastic-plastic structures under near-fault ground motions (Part 1: Fling-step input). Front. Built Environ. 2015, 1, 12. [CrossRef]

29. Makris, N.; Black, C.J. Dimensional analysis of rigid-plastic and elastoplastic structures under pulse-type excitations. J. Eng. Mech. 2004, 130, 1006-1018. [CrossRef]

30. Sasani, M.; Bertero, V.V. Importance of severe pulse-type ground motions in performance-based engineering: Historical and critical. In Proceedings of the 12th World Conference on Earthquake Engineering, New Zealand Society for Earthquake Engineering, Upper Hutt, New Zealand, 30 January-4 February 2020.

31. Akehashi, H.; Takewaki, I. Optimal viscous damper placement for elastic-plastic MDOF structures under critical double impulse. Front. Built Environ. 2019, 5, 20. [CrossRef]

32. Parmelee, R.A. The influence of foundation parameters on the seismic response of interaction systems. In Proceedings of the Third Japan Earthquake Engineering Symposium, Tokyo, Japan, 17-20 November 1970; Volume 3, pp. 49-56.

33. Akehashi, H.; Kojima, K.; Farsangi, E.N.; Takewaki, I. Critical response evaluation of damped bilinear hysteretic SDOF model under long duration ground motion simulated by multi impulse motion. Int. J. Earthq. Impact Eng. 2018, 2, 298-321. [CrossRef] 